\title{
DRUG RESEARCH METHODOLOGY. VOLUME FIVE. EXPERIMENTATION IN DRUGS AND HIGHWAY SAFETY: THE STUDY OF DRUG EFFECTS ON SKILLS RELATED TO DRIVING
}

\author{
Kent B. Joscelyn \\ Alan C. Donelson
}

The University of Michigan

Highway Safety Research Institute

Ann Arbor, Michigan 48109

Contract No.DOT HS-7-01530

Contract Amt. $\$ 234,000$

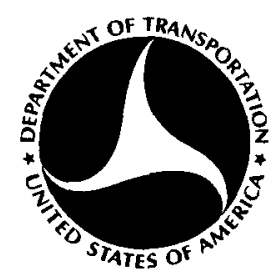

JUNE 1980

FINAL REPORT

\author{
This document is available to the U.S. public through the \\ National Technical Information Service, \\ Springfield, Virginia 22161
}

Prepared For

U.S. DEPARTMENT OF TRANSPORTATION

National Highway Traffic Safety Administration

Washington, D.C. 20590 
This document is disseminated under the sponsorship of the Departient of Transportation in the interest of Information exchange. The Unlted states Covernment assumes no liablilty for lts contents or use thereof. 
Techaical Report Documentation Page

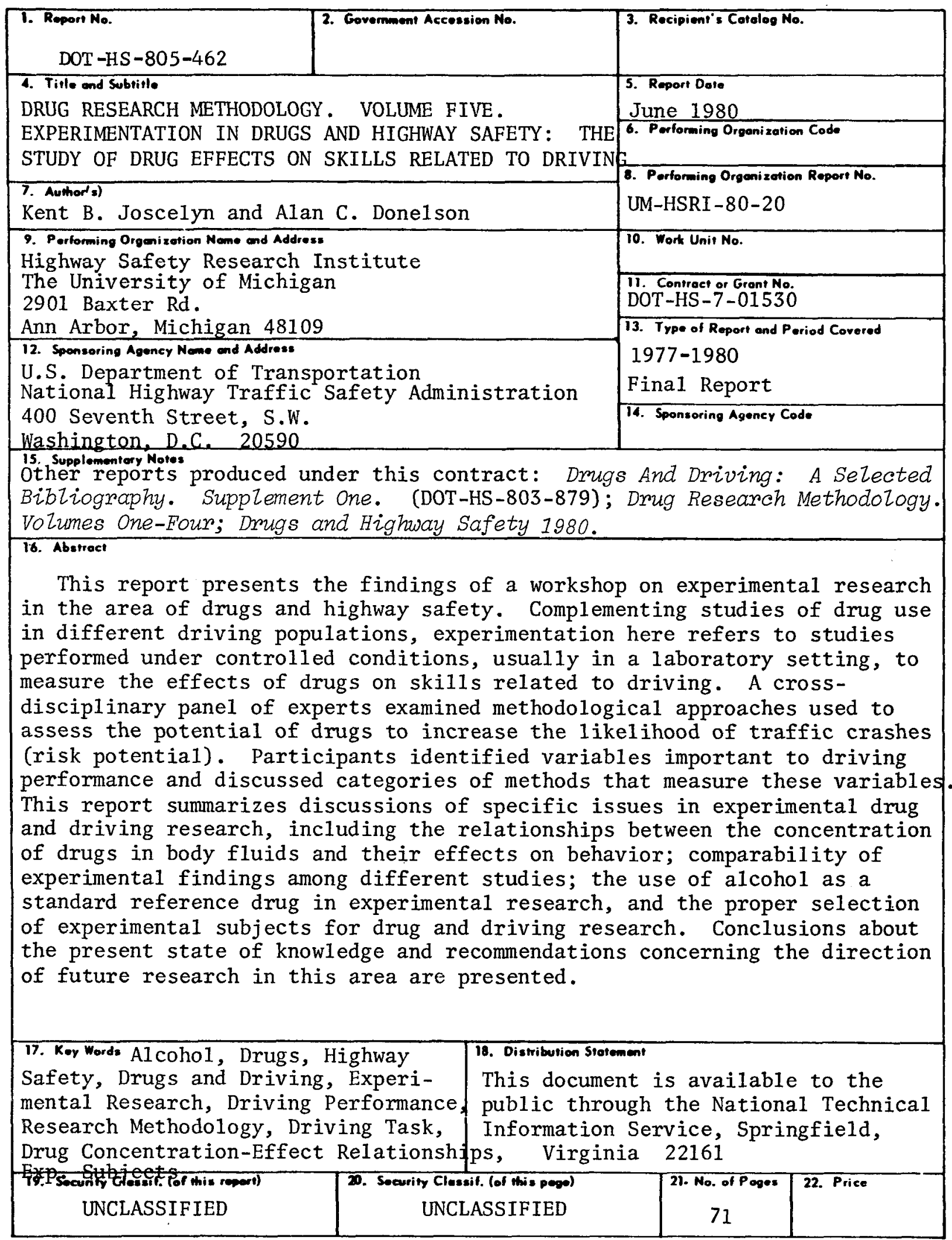




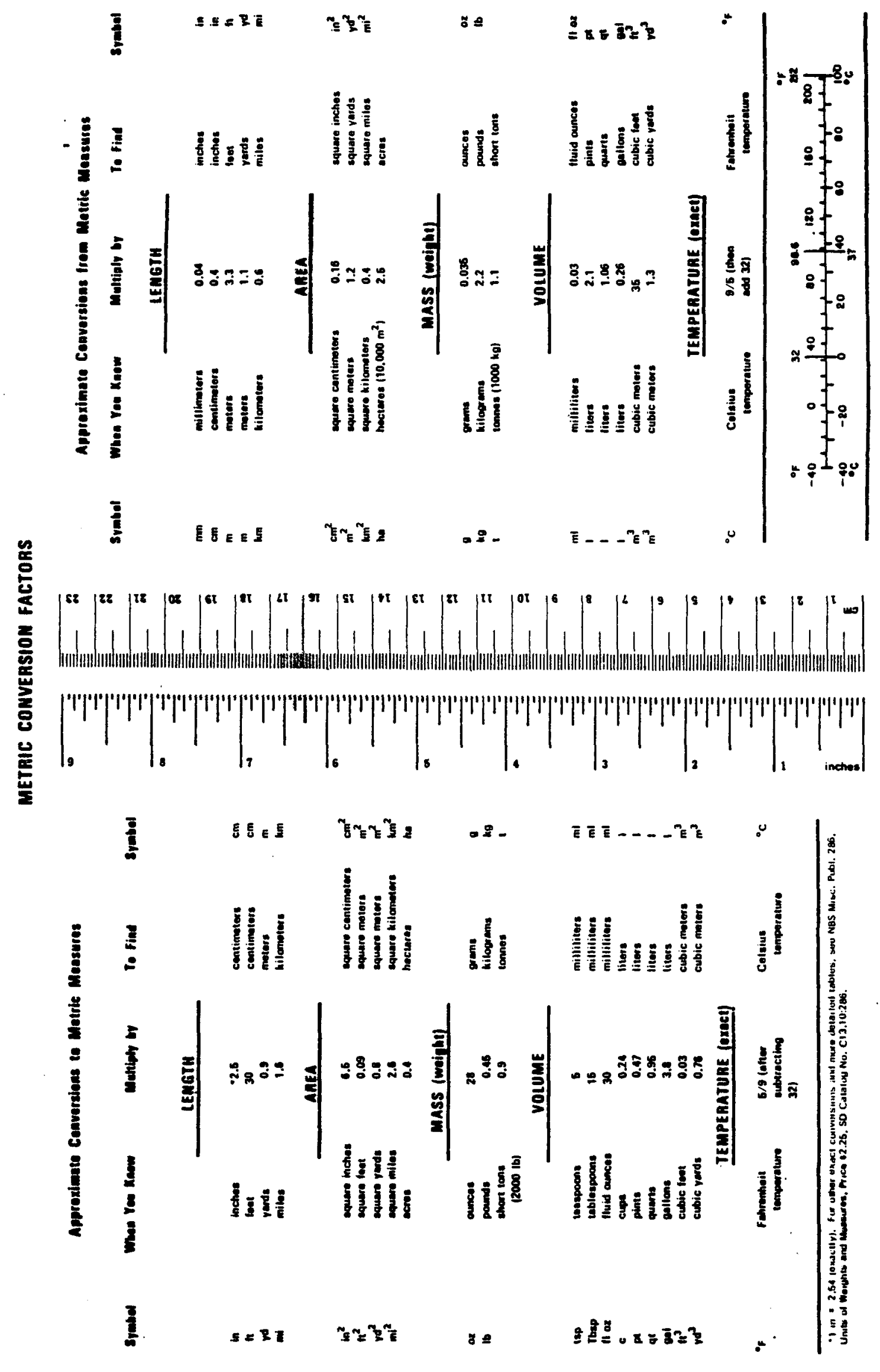




\section{ACKNOWLEDGMENT}

This report results from efforts by many persons and stems from their able and varied contributions. We thank all who assisted in its development, preparation, and production.

Special recognition is due to those who participated in the workshop and whose expert contributions formed the basis for the report:

- Stephen D. Benson

- David K. Damkot

- Leon G. Goldstein

- Rodger J. Koppa

- Norman A. Krasnegor
- Markku Linnoila

- Roger P. Maickel

- Herbert Moskowitz

- James C. Miller

- Robert E. Willette

Each of the participants gave generously of their knowledge and energy and often continued discussions after formal sessions had ended. Their willing support has made this report possible.

We gratefully acknowledge the staff of the Belmont Conference Center, whose gracious service contributed to a setting and atmosphere most conducive to productivity. We especially thank Mrs. Mary Force, director of the center, and Ann Higgins, our conference coordinator, both of whom greatly facilitated the planning and arranging of this workshop.

The technical approach of the project was designed by Kent B. Joscelyn and Roger P. Maickel. This report was drafted by Alan C. Donelson from notes and records of the workshop sessions. Early drafts of the report were reviewed by colleagues at The University of Michigan, in particular, Michael Sivak, Ph.D.

A working draft was circulated among participants, who reviewed it for accuracy and comprehensiveness. The final text was then prepared, based on their comments.

The comments of Stephen D. Benson, Ph.D., who also serves as Contract Technical Manager for this project, were particularly useful. 
Other HSRI personnel also made important contributions. This report was edited by James E. Haney. Anne L. VanDerworp served as production editor and produced the report with the assistance of Douglas $\mathrm{J}$. Van Den Berg. Draft versions of the report were produced by clerical staff of the Policy Analysis Division under the supervision of Janet $C$. Peters.

We thank all who contributed.

Kent B. Joscelyn

Principal Investigator

\author{
Alan C. Donelson \\ Principal Investigator
}


PREFACE

This report presents the results of one of a series of workshops on methodological issues in research on drugs and highway safety. The workshops addressed discrete--but interrelated--topics. The workshops were conducted by The University of Michigan Highway Safety Research Institute (HSRI) for the National Highway Traffic Safety Administration as part of a larger research program on drugs and driving.

A reader interested in the subject area will find the other workshop reports and technical reports produced under the research program of value. The workshop reports are:

- Drug Research Methodology. Volume One. The AlcoholHighway Safety Experience and Its Applicability to Other Drugs.

- Drug Research Methodology. Volume Two. The Identification of Drugs of Interest in Highway Safety.

- Drug Research Methodology. Volume Three. The Detection and Quantitation of Drugs of Interest in Body Fluids from Drivers.

- Drug Research Methodology. Volume Four. Epidemiology in Drugs and Highway Safety: The Study of Drug Use Among Drivers and Its Role in Traffic Crashes.

- Drug Research Methodology. Volume Five. Experimentation in Drugs and Highway Safety: The Study of Drug Effects on Skills Related to Driving.

Other reports prepared under the HSRI project include an annotated bibliography of literature on drugs and driving and related topies:

- Joscelyn, K.B., and Donelson, A.C. 1979. Drugs and Driving: A Selected Bibliography. Supplement One. National Highway Traffic Safety Administration technical report DOT-HS-803-879; 
as well as a comprehensive review of past, ongoing, and planned efforts related to the study of and the response to the drug and driving problem:

- Joscelyn, K.B.; Donelson, A.C.; Jones, R.K.; MeNair, J.W.; and Ruschmann, P.A. 1980. Drugs and Highway Safety 1980. National Highway Traffic Safety Administration contract no, DOT-HS-7-01530.

The latter report supported the preparation of a report to Congress by the Secretary of Transportation as requested in Section 212 of the Highway Safety Act of 1978. Both reports cited above developed from and extended similar work done under earlier contracts from NHTSA:

- Joscelyn, K.B., and Maickel, R.P. 1977. Drugs and Driving: A Research Review. National Highway Traffic Safety Administration technical report DOT-HS-802-189.

- Joscelyn, K.B., and Maickel, R.P. 1977. Drugs and Driving: A Selected Bibliography. National Highway Traffic Safety Administration technical report DOT-HS-802-188.

- Joscelyn, K.B., and Maickel, R.P., eds. 1977. Report On An International Symposium on Drugs and Driving. National Highway Traffic Safety Administration technical report DOT-HS-802-187.

- Joscelyn, K.B.; Jones, R.K.; Majckel, R.P.; and Donelson, A.C. 1979. Drugs and Driving: Information Needs and Research Requirements. National Highway Traffic Safety Administration technical report DOT-HS-804-774.

- Jones, R.K., and Joscelyn, K.B. 1979. Alcohol and Highway Safety 1978: A Review of the State of Knowledge. National Highway Traffic Safety Administration technical report DOT-HS-803-714.

- Jones, R.K., and Joscelyn, K.B. 1979. Alcohol and Highway Safety 1978: A Review of the State of Knowledge. Summary Volume. National Highway Traffic Safety Administration technical report DOT-HS-803-764.

- Jones, R.K.; Joscelyn, K.B.; and McNair, J.W. 1979. Designing A Health/Legal System: A Manual. The University of Michigan Highway Safety Research Institute report no. UM-HSRI-79-55. 
These reports provide entry points to the literature on alcohol, other drugs, and highway safety for readers desiring general reviews as well as information on specific topic areas. In addition, the reports can serve as sources for identifying both U.S. and foreign literature pertinent to each reader's needs. 


\section{CONTENTS}

1.0 INTRODUCTION 1

1.1 Background 1

1.2 Scope and Objectives of Preceding Workshops 3

1.3 Purpose of Workshop IV, Experimentation in Drugs and Highway Safety: The Study of Drug Effects on Skills Related to Driving 5

1.4 Scope of Report 8

2.0 REVIEW OF FINDINGS OF PREVIOUS WORKSHOPS 9

2.1 The List of Drugs of Interest 9

2.2 Comments by Participatns on Other Issues in Drug and Driving Research

3.0 METHODOLOGICAL APPROACHES TO EXPERIMENTAL RESEARCH ON DRUGS $\begin{array}{ll}\text { AND HIGHWAY SAFETY } & 15\end{array}$

3.1 Aims of Experimental Research on Drugs and Highway Safety 15

3.2 Assessing Drug Effects: Important Behavioral Factors 17

3.3 Assessing Drug Effects: Methodology 24

3.3.1 Tests of Specific Skills Related to Driving 24

3.3.2 Tests of Human Skills Using Driving Simulators 26

3.3.3 Tests of Driving Skills on Closed Courses 27

3.3.4 Tests of Driving Skills "On the Road" 28

3.4 Approaches to the Experimental Study of Drug Effects on Driving Performance $\quad 29$

3.5 Comparing Behavioral Methodologies: The State of Knowledge 38

3.6 Summary 40

4.0 OTHER ISSUES IN EXPERIMENTAL RESEARCH ON DRUGS AND HIGHWAY SAFETY 43

4.1 Comparability Among Experimental Studies 43

4.2 Alcohol as a Standard Reference Drug for Experimental 
Research on Other Drugs 44

4.3 The Selection of Experimental Subjects 45

4.4 The Face Validity of Experimental Research on Drugs and $\begin{array}{ll}\text { Highway Safety } & 47\end{array}$

4.5 Summary 48

5.0 CONCLUSIONS AND RECOMMENDATIONS

APPPENDIX A--LIST OF WORKSHOP IV PARTICIPANTS

BIBLIOGRAPHY $\quad 61$ 


\subsection{INTRODUCTION}

This report presents the findings of $\mathbf{a}$ workshop on experimental research in drugs and highway safety. The workshop was held on 19-21 June 1978 at the Smithsonian Institution's Belmont Conference Center, Elkridge, Maryland. The workshop was one of a series conducted by the Policy Analysis Division of The University of Michigan, under the sponsorship of the U.S. Department of Transportation, National Highway Traffic Safety Administration contract DOT-HS-7-01530.

\subsection{Background}

The extent to which the use of drugs by drivers contributes to highway safety problems is unknown (Joscelyn and Maickel 1977a; Willette 1977; Organisation for Economic Co-operation and Development 1978; Seppala, Linnoila, and Mattila 1979; Joscelyn, Jones, Maickel, and Donelson 1979). Research has not established that any drug besides alcohol increases the probability of a traffic crash and associated losses. (The term "alcohol" is used here and throughout this report to mean ethyl alcohol, or ethanol.) Although present knowledge about drugs and driving is limited, available evidence indicates that drugs alone or in combination with alcohol or other drugs can impair driving skills and may increase the likelihood of traffic crashes. Further inquiry in this area is warranted. Among the factors that limit the state of knowledge are problems and issues in major areas of drug and driving research.

In November 1976, The University of Michigan Highway Safety Research Institute (HSRI) received a contract entitled "Drug Research Methodology" from the National Highway Traffic Safety Administration (NHTSA). Its general objectives are:

- to develop a greater understanding of the nature of the drug and driving problem on the basis of existing literature; and 
- to define directions for future research with greater precision than has been done in the past NHTSA-sponsored efforts.

The project emphasizes the generation of possible solutions to research issues in drugs and highway safety. The overall task is to identify and develop methodologies for research in drugs and driving. Specific objectives of this study are:

- to identify problem areas that should be addressed in drug methodology;

- to identify alternative approaches to research that could be implemented with current technology; and

- to provide a listing of priority items of research that NHTSA could address in the foreseeable future.

To accomplish these objectives, an approach based on workshops was used to examine issues in four distinct but interrelated areas:

- The Identification of Drugs of Interest in Highway Safety;

- The Detection and Quantitation of Drugs of Interest in Body Fluids from Drivers;

- Epidemiology in Drugs and Highway Safety: The Study of Drug Use Among Drivers and Its Role in Traffic Crashes; and

- Experimentation in Drugs and Highway Safety: The Study of Drug Effects on Skills Related to Driving.

The division of topies had advantages as well as a possible disadvantage. For example, on one hand, a tighter focus on specific issues could be achieved. On the other hand, for some topies the wisdom and expertise of participants in other workshops might be lost. To offset this disadvantage, summaries of earlier workshops were mailed to invitees, and participants were later asked to comment on findings as well as issues in those areas.

These workshops, conducted in the spring and summer of 1978, were highly productive and brought to focus other issues in related areas of 
drugs and driving. In 1978, a contract modification called for additional workshops within the scope of the statement of work. In January 1978, a fifth workshop dealt with the alcohol and highway safety experience and its relation to the study and control of the drug and driving problem. The remaining workshops will address other topies of priority interest to NHTSA.

These workshops constitute a series in which each is an integral part. Although the workshops were self-contained and are reported in separate volumes, in general the progression of topics has been systematic. An apparent exception is Workshop V, reported as Volume One. This deserves some explanation. References and comparisons to the study of, and the response to, the alcohol-crash program occurred frequently during the first four workshops. In fact, public sensitivity to the alcohol-crash problem has itself led to an awareness that other drugs also have the potential to increase traffic crash risk. Workshop $\mathrm{V}$ was therefore planned to examine the alcohol and highway safety experience in detail. As Volume One, the report on workshop $\mathrm{V}$ serves as an introduction to the others, provides a historical perspective, and describes the relation of the alcohol and highway safety experience to other drugs. The workshop reports are designed to be read sequentially. Nevertheless, a reader desiring information on a specific topic area can refer to the particular volume of interest.

Another task under this contract is to update the literature review performed for NHTSA under contract DOT-HS-4-00994 (Joscelyn and Maickel 1977b). A report produced under this contract (Joscelyn and Donelson 1979) presents an annotated bibliography of recent literature on drugs and driving to supplement the parent volume. Another in this series of bibliographic reports is planned for publication in the summer of 1980 .

\subsection{Scope and Objectives of Preceding Workshops}

The first workshop, The Identification of Drugs of Interest in Highway Safety, addressed the question of which drugs should be considered in the study of methodological and other issues. Its purpose was to identify drugs 
(1) that should be the focus of near-term, NHTSA-sponsored research on drugs and driving, and (2) that should be the focus for discussing research issues in the other workshops. Two objectives of the first workshop were:

- to develop a way to estimate the risk potential of drugs, based on an approach that formulates subjective judgments of experts and that synthesizes present knowledge in distinct fields related to drugs and driving; and

- to produce an initial rank ordering of identified drugs of interest, based on subjective estimates of their risk potential.

One output of Workshop I, the list of drugs of interest, became a basis for discussion in the second workshop. It served to identify drugs with greater perceived risk to highway safety, thus guiding the emphasis of discussion in this and the other workshops.

Workshop II dealt with methods of analysis for drugs in human body fluids. In the context of epidemiologic and experimental research to define the drugs and driving problem, the purposes of Workshop II were these:

- to identify problem areas and research issues related to the analysis of body fluids for drugs;

- to provide detailed and workable approaches to resolving analytical problems; and

- to suggest research to resolve methodological issues.

Its specific objectives were as follows:

- to outline analytical requirements for research in drugs and highway safety;

- to identify techniques and methods to detect and quantitate the drugs of interest;

- to provide alternative solutions for other problems pertaining to analysis of drugs (e.g., collection, handling, and storage of specimens; testing of laboratories for proficiency). 
Output of Workshop II, for example, approaches to screening body fluids for drugs, fed into the third workshop, described below.

Workshop III focused on epidemiology in drugs and highway safety. One of two major approaches to research in this field, surveys of drug use in driving populations present great difficulty. Problems with existing data arise in part from methods of drug analysis employed in past studies. But other issues and constraints in this research area also hamper progress. The purpose of the third workshop, therefore, was to resolve these issues to the extent possible. Its objectives were the following:

- to identify methodological and other issues in research to indicate the highway safety risk of drugs;

- to suggest approaches to resolving problems in the design and conduct of epidemiologic studies; and

- to recommend research needed in this area.

The main emphasis was on epidemiologic approaches and their constraints.

1.3 Purpose of Workshop IV, Experimentation in Drugs and Highway Safety: The Study of Drug Effects on Skills Related to Driving

The other major approach to the study of drugs and highway safety is experimentation. Although most research involves experiments of some kind, here the term experimental research refers to studies performed under controlled conditions, usually in a laboratory setting, to measure the effects of drugs on driving-related skills. A specific application of the experimental approach is the study of relationships between amounts of drugs consumed or present in body fluids and their effects on driving skills (dose-response, concentration-effect relationships). The central aim of experimentation in drugs and highway safety is to assess the potential of drugs to increase highway safety risk.

Reviews of experimental research on the effects of drugs reveal a voluminous but disjointed body of facts (Joscelyn and Maickel 1977a; Organisation for Economic Co-operation and Development 1978; Seppala, Linnoila, and Mattila 1979; Willette 1977; Joscelyn et al. 1979). Research 
in this area has been unsystematic; separate studies are rarely comparable. One reason is that methods for behavioral research and drugs for study are both numerous and diverse. For example, a broad range of techniques has been employed in the study of drug effects, from actual driving to simple tests of psychomotor skills. At the same time, studies best designed to compare the effects of drugs--those that measure the amount of drugs in body fluids and the magnitude of effects over time--are least in evidence. Present knowledge of drug effects on driving-related skills is thus fragmentary and incomplete.

Major problem areas exist in the experimental study of drug effects on driving performance. Because personal, vehicular, and environmental factors all play roles in driving, the driving task is complex and resists complete analysis. The study of driving performance presents not only theoretical but also practical problems. Testing for drug effects under actual driving conditions raises safety, legal, and ethical issues. But alternatives, for example, tests on closed driving courses and driving simulators, cannot reproduce the actual driving task in its entirety and lack the element of risk that actual traffic situations provide. Simpler tests of behavior may tap skills important in driving, but little is known about how the effects of drugs measured by these methods relate to the consequences of drug use in actual driving. Moreover, during behavioral testing, volunteer subjects may be motivated to perform their best, a factor probably missing in routine driving. Another complication that may arise is the ability of subjects to compensate for some effects of drugs on specific driving skills. Thus, the validity of experimental methods to assess drug effects on driving performance has been called into question.

The purpose of Workshop IV, therefore, was to resolve, where possible, methodological issues in experimental research in drugs and driving. Its objectives were:

- to identify issues in measuring drug effects on drivingrelated skills;

- to propose approaches to resolving specific problems in measuring the effects of drugs on driving-related skills; and 
- to suggest further research in this area.

One expected output of this workshop was an identification of valid surrogate measures of driving performance for testing drugs that may increase highway safety risk. The design and conduct of future experiments were also of special concern.

To accomplish these aims, experts were needed from areas of basic and applied research, both directly and indirectly related to drugs and driving. Knowledge of behavioral methodology and of the effects of drugs was required. As a group, participants had to be familiar with methods now used to test driving-related skills. Because most drug use occurs for reasons related to health, clinical as well as behavioral aspects of pharmacology were important. Participants were selected on this basis.

The participants of Workshop IV represented many disciplines, including behavioral and social psychology; basic and applied physiology; pharmacology, including psychopharmacology and clinical pharmacology; toxicology; and engineering psychology, i.e., human factors research. participants were active in many areas of research, including the following:

- accident provention and safety;

- driver education and improvement;

- driver behavior and highway safety;

- driving in emergency situations;

- accident countermeasures;

- drugs and behavior, both basic research and clinical aspects; and

- drugs and driving.

The panel as a whole had direct experience with the full range of approaches and methods in the study of driving performance, from on-theroad testing to laboratory tasks. Several members of the panel were actively engaged in the development of methods to apply in their research 
on the effects of drugs and other conditions on driving performance. So the expertise of participants of Workshop IV included experimental research on drugs and driving as well as basic and applied research on behavioral methodology related to driving performance.

The participants, from both inside and outside the government, functioned as an interdisciplinary group in an informal workshop setting. A moderator with an extensive background in the area of alcohol, drugs, and highway safety functioned as "lowest common denominator." The moderator served (1) to link panel members from different areas of research, (2) to provide a ground for basic understanding in a manydisciplined group, and (3) to ensure that the workshop's procluct could be used by a general audience.

\subsection{Scope of Report}

This report has five sections. The four that follow are briefly described below.

Section 2.0, Review of Findings of Previous Workshops, summarizes comments by the panel of Workshop IV.

Section 3.0, Methodological Approaches to Experimental Research on Drugs and Highway Safety, outlines behavioral elements of the driving task for evaluating the effects of drugs on driving performance and describes classes of methodology applicable to drug and driving research. Also discussed are possible strategies for experimental programs to assess the potential highway safety risk of drugs.

Section 4.0, Other Issues in Experimental Research on Drugs and Highway Safety, concerns general problems related to methodology in this area of research.

Section 5.0 presents the conclusions and recommendations of the panel.

Appendix A provides a list of participants of Workshop IV. 


\subsection{REVIEW OF FINDINGS OF PREVIOUS WORKSHOPS}

The Drug Research Methodology project includes a series of workshops on distinct but interrelated areas of drug and driving research. Section 1.1 briefly describes efforts to obtain input on issues from participants in other workshops. Thus, the panel of the fourth workshop was asked to review and comment on findings of the previous workshops. In addition to the list of drugs of interest produced in Workshop I, participants discussed more general issues concerning drugs and highway safety.

\subsection{The List of Drugs of Interest}

As a frame of reference for comments on the list of drugs of interest, the purpose, approach, and findings of Workshop I were briefly outlined. (For a detailed discussion of these topics the reader is referred to the report on Workshop I [Joscelyn and Donelson 1980]. See also Section 1.2 of this report.) Table 2-1 presents the rank order of drugs of interest developed in Workshop I. (The word "drug" is used here and throughout this report in its most generic sense; that is, substances not usually considered drugs were included in its meaning, e.g., volatile solvents and carbon monoxide. Drugs of interest are those that have the potential to increase the likelihood of traffic crashes and concomitant losses.)

Prior to discussing the list of drugs of interest, two points were stressed. First, the drug or group of drugs actually ranked are listed in column two of Table 2-1. As indicated in Table 2-1, the third column lists examples either drawn from discussion during the rating process or selected later by HSRI staff to represent subclasses of drugs within each group. Second, the rating procedure produced subjective estimates of the potential of a drug (or group of drugs) to increase highway safety risk, relative to alcohol. Separate ratings of two categories of criteria--termed Exposure and Effects--were combined to facilitate the rank ordering of 
TABLE 2-1

A RANK ORDERING OF THE DRUGS OF INTEREST

\begin{tabular}{|c|c|c|}
\hline RANK & 1 & FYAMDT FC \\
\hline ORDER & DRUG OR DRUG GROUPING & EXAMPLES * \\
\hline 1 & ethanol & $\{$ alcoholic beverages \\
\hline 2 & $\left\{\begin{array}{l}\text { diazepam (Antianxiety Agent, } \\
\text { Group I) }\end{array}\right.$ & i \\
\hline 3 & I cannabis sativa & | marijuana, hashish \\
\hline 4 & $\begin{array}{l}\text { codeine (Narcotic Analgesic, } \\
\text { Group I) }\end{array}$ & 1 \\
\hline 5 & $\left\{\begin{array}{l}\text { i Volatile Solvents } \\
1 \\
1\end{array}\right.$ & $\left\{\begin{array}{l}\text { xylene, gasoline, toluene, } \\
\text { butylnitrite, } \\
\text { trichloroethylene }\end{array}\right.$ \\
\hline 6 & $\left\{\begin{array}{l}\text { flurazepam (Sedative-hypnotic, } \\
\text { Group I) }\end{array}\right.$ & $\vdots$ \\
\hline 7 & $\left\{\begin{array}{l}\text { d-propoxyphene (Narcotic Analgesic, } \\
\text { Group I) }\end{array}\right.$ & 1 \\
\hline 8 & $\left\{\begin{array}{l}\text { Antihypertensives } \\
\mid\end{array}\right.$ & $\begin{array}{l}\text { reserpine, propranolol, } \\
\text { hydralazine, methyldopa, } \\
\text { digoxin }\end{array}$ \\
\hline 9 & $\begin{array}{l}\text { oxycodone (Narcotic AnaIgesic, } \\
\text { Group II) }\end{array}$ & i \\
\hline 9 & $\left\{\begin{array}{l}\text { Sedative-hypnotics, Group IIa } \\
\mid\end{array}\right.$ & $\begin{array}{l}\text { secobarbital, pentobarbital, } \\
\text { amobarbital (inclusive) }\end{array}$ \\
\hline 10 & $\left\{\begin{array}{l}\text { chlordiazepoxide (Antianxiety Agent, } \\
\text { Group I) }\end{array}\right.$ & i \\
\hline 11 & $\begin{array}{l}\text { Antihistamines, Group I } \\
\text { (over-the-counter) }\end{array}$ & $\begin{array}{l}\text { diphenhydramine, } \\
\text { chlorpheniramine, } \\
\text { methapyrilene, doxylamine }\end{array}$ \\
\hline
\end{tabular}


TABLE 2-1

A RANK ORDERING OF THE DRUGS OF INTEREST (Continued)

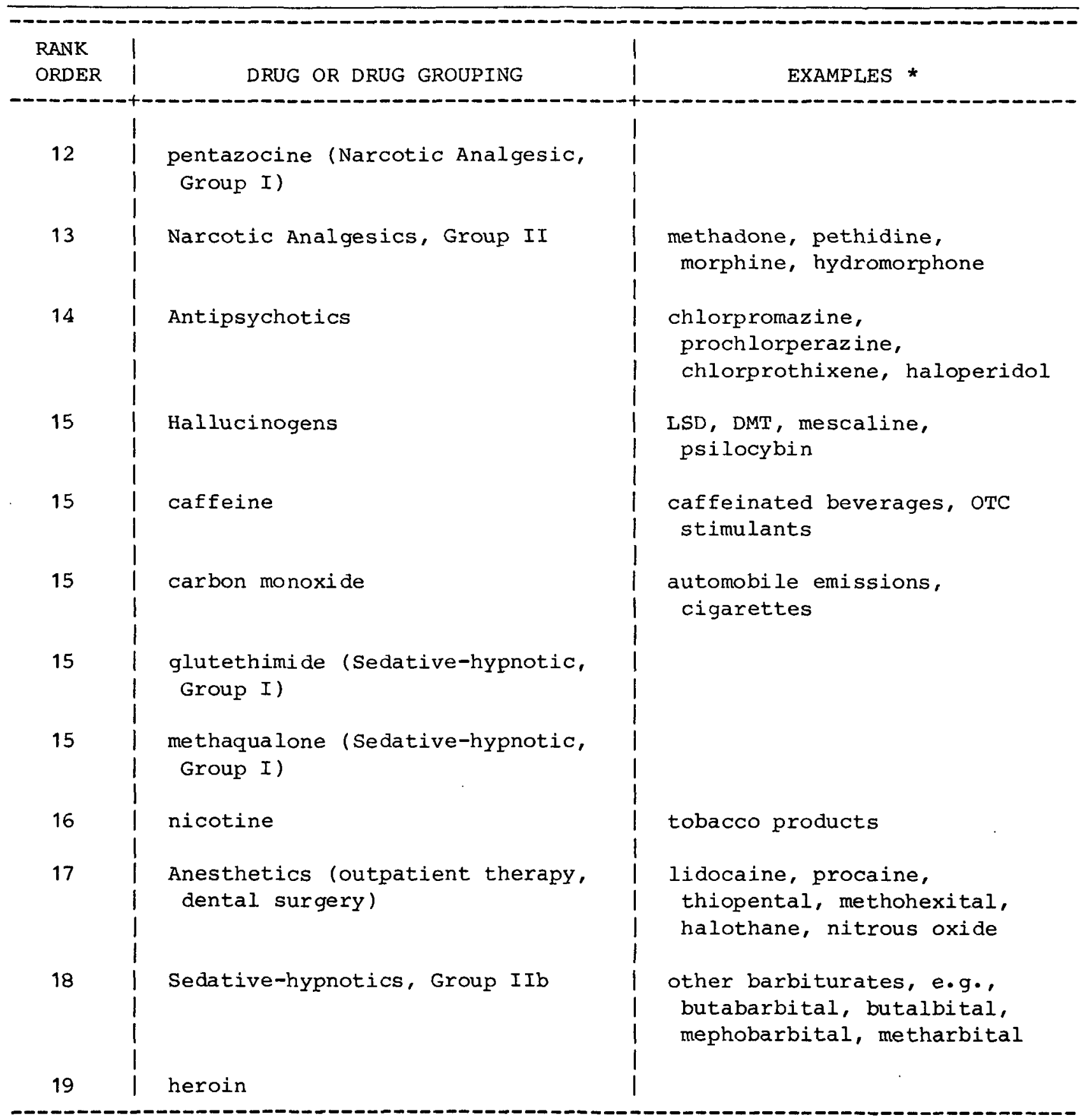


TABLE 2-1

A RANK ORDERING OF THE DRUGS OF INTEREST (Continued)

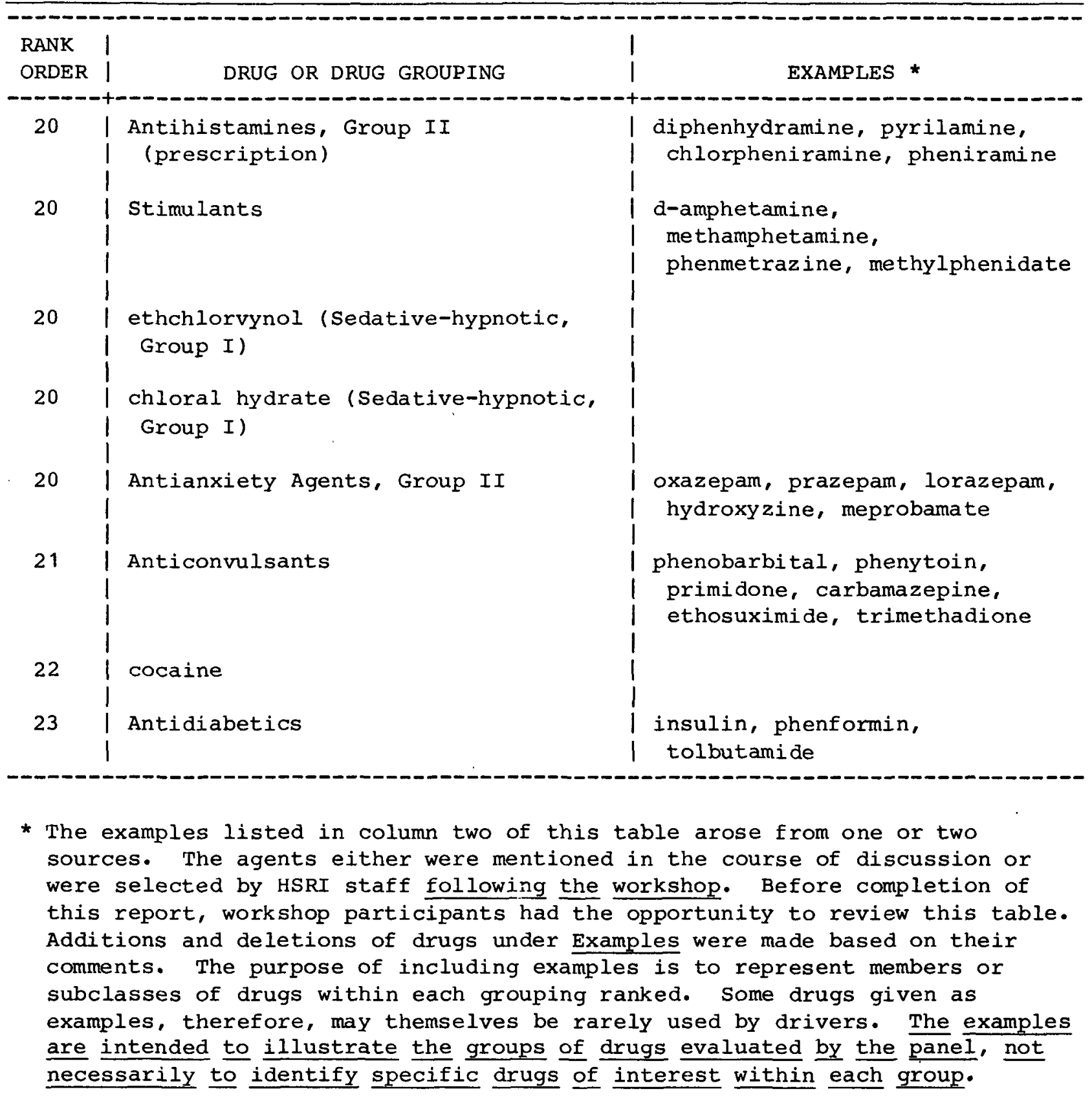


the drugs of interest.

Two questions were then posed to the panel of Workshop IV:

1. Were any important drugs or classes of drugs missing from the list of drugs of interest?

2. Were any drugs or classes of drugs out of order, or should any now listed be dropped from the list?

In response to the first question, participants noted the absence of nitrogen oxide ( $\mathrm{NO})$ and nitrogen dioxide $\left(\mathrm{NO}_{2}\right)$, gases with potentially harmful effects found in the exhaust of gas combustion engines (along with carbon monoxide). Also missing, they pointed out, was nitrous oxide $\left(\mathrm{N}_{2} \mathrm{O}\right.$, "laughing gas"), an anesthetic agent also used as a "recreational" drug.

With regard to the second question, participants asked about the listing of caffeine and nicotine. The listing of drugs such as caffeine and nicotine was explained as the attempt by participants of the first workshop to provide reference points in the overali rank order of the drugs of interest. Not every drug listed is expected to be the focus of drug and driving research. Rather, the list would serve as a guide for selecting drugs, subject to change as the state of knowledge advanced. At the same time, some substances mentioned in the literature as drugs for study did not appear to warrant as much concern as often expressed. So the inclusion of caffeine and nicotine was intended to indicate the relative, perceived importance of other drugs, such as cocaine and antidiabetic agents.

The rank order of the antidiabetic agents, volatile solvents, and methadone concerned some participants. One member of the panel stated that because diabetic patients have the highest accident rate among groups in medical treatment, the ranking of antidiabetic drugs should be higher. Others suggested that the ranking of volatile solvents and methadone should be ranked lower relative to other drugs. 


\subsection{Comments by Participants on Other Issues in Drug and Driving}

\section{Research}

Besides the list of drugs of interest, participants briefly discussed other research issues in drugs and driving. They emphasized the need for both epidemiologic and experimental approaches. Concerning surveys of drug use among drivers, they stressed that populations of drivers other than those fatally injured must eventually be studied. Because samples of fatally injured drivers may be atypical compared to the crashed driving population as a whole, they may not accurately reflect the nature and extent of the drug and driving problem.

A question about the size of samples needed in epidemiologic studies arose. Given the relatively low frequency of use of some drugs by the general population, a concern was that very large numbers of cases would be required to obtain meaningful results. It was pointed out, however, that the distribution of drugs in accident-involved driving populations may differ from that in the general population. If sampling strategy were based on estimates of drug use in the latter population, much larger samples than realistically needed might result. On the other hand, if smaller samples were drawn, and if certain drugs were detected with a prevalence greater than expected on the basis of their patterns of use, these findings would indicate overinvolvement in the crash population.

Participants pointed out sources of information about the relationship between drugs and highway safety other than epidemiologic and experimental research. Sources of these data may include the Bureau of Labor Statistics, the National Association of Manufacturers, the National Institute of Occupational Safety and Hazards, and corporations that have programs to monitor drug-related events among employees. Input of collateral data on the influence of drugs in related areas like industrial settings may help indirectly to suggest the possible outlines of a drug and driving problem.

Other subjects in these preliminary discussions pertained to the main topic of this workshop. These are treated in the following sections. 


\subsection{METHODOLOGICAL APPROACHES TO EXPERIMENTAL RESEARCH ON DRUGS AND HIGHWAY SAFETY}

As defined in Section 1.2 the term experimental research refers to studies performed under controlled conditions to measure the effects of drugs on skills related to driving. Since most research can be said to involve experiments of some kinds, participants further characterized this major approach. Intervention by the researcher, as opposed to observation only, distinguishes experimentation from epidemiologic approaches. An important element in experiments is the assignment of treatment to subjects. When treatment cannot be assigned, a series of problems ensues, including the control of variables that may be important factors in a study. The experimental model is approximated in some surveys, for example, by matching subjects on certain characteristics. But approximating the experimental model, in the view of the participants, is not doing an experiment. So on outlining methodological approaches to experimental research on drugs and highway safety, participants discussed ways to study the effects of drugs in the context of experimentation as defined above. (The distinction between experimentation and epidemiology, however, is not absolute. See the discussion of "experimental epidemiology" by MacMahon, Pugh, and Ipsen [1960] .)

\subsection{Aims of Experimental Research on Drugs and Highway Safety}

The aims of experimental research on drugs and highway safety formed the basis of discussion. Two purposes of experimental studies were described. One purpose is to identify drugs that have the potential to substantially increase the likelihood of traffic crashes and concomitant losses among drivers using them. The other purpose is to provide the means for interpreting drug concentrations in body fluids from drivers. Assumed for the purposes of discussion was that some drugs will be more 
prevalent in populations of accident-involved drivers compared to the nonaccident driving population and that these drugs will be the focus of in-depth, comprehensive experimental study. The statistical overrepresentation of factors in the causation of accidents is one accepted indicator of risk in highway safety and provides justification for further inquiry.

One participant pointed out that the aims of experimental drug and driving research may influence the choice of methodology for the study of drug effects. He contrasted the prediction of accident frequency with the assessment of drug effects. Few tests or batteries of tests do well in correlating the performance of human skills and accident records. This is due in part to the poor reliability of accident records as a measure of human behavior. Moreover, traffic crashes occur for other reasons besides stable characteristics of human behavior. Nevertheless, a rational view states that any condition or drug that changes performance of some human skill important to driving can be a potential hazard. For example, while visual acuity itself does not correlate well with accident frequency, any drug that produces blurred vision would be considered dangerous to traffic safety. The same applies to reaction time. The natural reaction time of drivers is not highly correlated with accident experience but conditions that delay a driver's responses must be regarded as hazardous. In addition, overreaction (too fast as well as overcontrol) can be just as disruptive. So methodology used to measure variables poorly correlated with accident frequency may still prove important in assessing the effects of drugs on driving performance.

The aim of assessing the highway safety risk potential of drugs led to the question of how experimental measures of human skills relate to actual driving performance. In the past, however, experimentation in drugs and highway safety has emphasized the effects of drugs per se over the relevance of test measures to the driving task. Few studies have examined this latter question. Unfortunately, judgments concerning methodology in experimental research must be based on limited information about their relevance to driving performance. 
To further focus discussion, participants were asked a series of related questions:

- Which skills related to driving should be measured with existing methodology and how should they be measured?

- Can the numerous skills related to driving be limited to a discrete set for the purpose of initially testing the effects of drugs?

- Given limited funds and the need to assess the risk potential of drugs, which methods are best for studying the effects of drugs in relation to the driving task?

- How can changes in selected test measures be equated to the probability of accidents?

- Which human performance variables should be measured with existing methodology and how should they be measured?

- Can behavioral variables related to driving be limited to a restricted set at least for initial testing of drug effects?

- Given limited funds and the need to assess the risk potential of drugs, which methods are best for studying the effects of drugs in relation to the driving task?

- How can changes in selected test measures be equated to the probability of accidents?

\subsection{Assessing Drug Effects: Important Behavioral Factors}

Responding to the question of which skills related to driving performance should be measured in studying drug effects in relation to the driving task, participants named almost twenty. Table 3-1 lists those mentioned in the course of discussion. (It is difficult to find a single, allinclusive term--for example, ability, skill, variable, behavioral function--to describe the range of behavioral, mental, psychomotor, and physiological factors listed in Table 3-1. For convenience the term factors is used.) Certain of the terms (for example, divided attention, information processing, perception, visual perception, risk-taking, visual vigilance, and decision-making) may be discrete but not necessarily independent. Some factors listed in Table 3-1 could be more properly termed "dependent 
TABLE 3-1

BEHAVIORAL FACTORS IMPORTANT FOR THE STUDY OF DRUG EFFECTS IN RELATION TO THE DRIVING TASK

Vigilance (Visual, auditory)

Attention

Divided Attention

(Rate of) Information Processing

Information Load Capacity

Visual Perception

Peripheral Visual Perception

Auditory Perception

Signal Detection

Eye Movements (duration of fixation, spatial distribution, saccades, pursuit velocity, nystagmus)

Response Time (reaction time)

Tracking

Physiological State (circadian [24-hour] rhytms, fatigue, stress hormones, EEG arousal time)

Ability to Compensate (for drug effects, other conditions)

Risk Taking

Decision Making

Driving Maneuvers

Cognition

Judgment 
measures." For example, response time may be a function of higher order cognitive abilities or skilis, like sensory perception and the rate of information processing. Some terms used by participants were quite broad, like tracking. "Tracking" is an important part of the driving task but how this variable is operationally defined depends on the method used to measure it. Other variables may require a more indirect approach. Comparing reports by subjects of their performance with objective measures provides one way to evaluate the effects of drugs on judgment, risk taking, and the ability to identify and compensate for the effects of drugs and other conditions. Finally, certain "variables" were described in tautologous terms derived from the methodology for measuring them; "driving maneuvers" and "eye movements" are examples. Although some factors listed in Table 3-1 appear far removed from skills related to driving, in the view of the participants, many of them represent elementary analogs of the driving task.

Even variables described as dependent measures are important, though. Psychotropic drugs primarily affect mental functions or processes otherwise not subject to observation. For example, one concern in driving performance is how information from the visual field is handled by drivers. Observations of eye movements provide measures of the distribution of attention and, indirectly, the rate of information processing. With eye movement techniques, therefore, the effects of drugs on the ability of subjects to divide attention and process information may be inferred. The involvement of peripheral vision, however, may complicate interpretation of eye movement studies.

The present state of the art in methods and techniques to measure some behavioral variables is limited. Assessment of drug effects on specific variables related to perception is very difficult. As illustrated above, inferences about changes in these variables are usually based on data obtained with indirect measures. The nature of these inferences largely depends on experimental paradigms and the methodology employed. In relation to the driving task, how well the measurement of eye movements corresponds to specific changes in mental function is one of 
many questions that research on behavioral methodology must answer.

Thus, basic research on behavioral methodology is very relevant to the area of drugs and driving. Present evidence from the analysis of accidents supports the inclusion of such behavioral variables as information processing among variables important to the study of drug effects. Some studies have shown a greater prevalence of psychotropic drugs in urban accidents than in rural accidents. The distribution of drug use among drivers involved in urban and rural accidents may be due to different patterns of drug use in urban and rural areas. However, because the denser traffic of urban driving results in a greater load on the capacity to process information, this factor and its influence by drugs should studied. On the other hand, analyses of rural accidents show that studies should also emphasize such variables as vigilance and physiological conditions like fatigue. Evidence for the involvement of impaired cognitive functions in the causation of accidents accents the need for research to develop better methods to measure these variables and changes due to the effects of drugs.

Participants stressed, however, that the present state of knowledge permits no one to state with certainty which set of factors or variables must be measured to assess adequately the highway safety risk potential of drugs. One approach to extending knowledge about human factors associated with the traffic crashes is the investigation of accidents in the field setting, comparing drug- and nondrug-involved crashes. Given the state of the art in accident analysis, however, human behavior associated with traffic crashes cannot be precisely defined. Although participants noted a "relative advancement" in accident investigations, resulting in better correlations between crashes and the performance of driving skills, they described this progress as insufficient to provide behavioral analyses of adequate depth. For example, the process of clinically assessing accidents involves three levels of investigation: examination of police accident reports; technicians' field survey; and in-depth investigation by multidisciplinary teams. Substantial variance in findings exists at all but the top level. Top level analyses show great involvement of human 
factors--in excess of eighty to ninety percent--and indicate, too, the substantial involvement of behavioral variables related to perception and information processing. But more in-depth analyses lack this kind of certainty. The interaction of environmental and subject-related factors contribute to this uncertainty.

The state of knowledge of the driving task itself hampers in-depth analyses of accidents. Not enough is known yet about the cognitive, perceptual, and emotional demands of driving. Although studies of the driving task have been performed, past analyses have been done for purposes other than defining variables for the study of drug effects. For example, detailed analyses of the driving task have been done for driver education programs. But drugs act on the behavioral capabilities of the body-not on behavior itself. Drugs influence behavior by altering one's ability to respond to behavioral demands, and their effects are expressed in (driving) behavior. For example, as one participant observed, drugs do not act on making left-hand turns.

This distinction is useful, especially since the direct study of drug effects on driving appears infeasible. The study of drug effects on measures of performance related to driving takes place out of normal traffic settings. (Even driving tests on the open road employ dual-control vehicles or in-the-car observers, which probably affect subjects' normal driving patterns by influencing their motivation to perform. The study of drug effects on driving on the open road raises serious legal, ethical, and practical issues, and this kind of study is rarely done.) The requirement to conduct research in artificial, driving-like settings complicates inference from drug effects on discrete measures of performance to drug effects in relation to the driving task itself. It is essential, therefore, to identify important factors common both to driving and to experimental methods. Although drug effects on actual driving cannot be inferred with absolute certainty (for example, one may well be able to compensate for certain skill decrements), an indication of a drug's risk potential can be gained. Factors like those listed in Table 3-1 can be defined for the study of behavioral functions--psychological, psychomotor, and physical processes- 
that permit performance of specific driving tasks, like left-hand turns. The relative importance of these factors, however, remains unknown.

Participants stressed that, as the state of knowledge advances, the list in Table 3-1 will probably expand to include other factors. New drugs with new kinds of effects may appear in use, affecting behavioral variables now unknown or currently considered fairly irrelevant to driver safety. Information from the literature on the action and effects of drugs may indicate their potential for driver impairment. Methods for testing their impairment characteristics would then be required.

Participants briefly attempted to classify the factors described as important to driving performance. A general behavioral scheme was suggested (Table 3-2). Its generality, however, required that more specific areas be defined. Another scheme distinguished between behavioral variables or functions, the fundamental factors under study, and response variables, the variables actually measured by a behavioral method or test. This way of classifying variables is illustrated in Table 32 .

Three issues complicated attempts to classify factors important to driving performance. One, concepts underlying identified factors are imprecise, and still subject to debate in the area of psychology. How to distinguish sensory perception and higher forms of mental activity (for example, cognition that occurs after sensory input) is largely unresolved. Two, paradigms with which to infer changes in behavioral variables from measures of response variables are in the process of evolving. While the involvement of higher cognitive functions is evident from experimental research, more research is needed to define the relationship between these two sets of variables. Three, response variables are largely defined by the methodology used to measure them. The techniques and methods employed vary with the area of research and the purpose of experimentation. What is inferred from measurements of eye movements, for example, may differ in studies of reading behavior and studies of driving-related skills.

A fourth issue-the existence and use of many techniques and methods for measuring a given factor or variable--led to discussions of methodology 
TABLE 3-2

TWO SCHEMES FOR CLASSIFICATION OF FACTORS

IMPORTANT TO DRIVING PERFORMANCE

\section{SCHEME 1}

\section{Genera1 Behavioral Categorization}

1. Input/Detection of Information

2. Information Processing

3. Decision Making

4. Response (Performance)

SCHEME 2

Behaviora1 Variable or Function [measured as] Response Variable

For example:

- Divided Attention

Information Sampling . . . . . Eye Movements

- Psychomotor Coordination . . . . Tracking

- Signa1 Detection

Information Load Capacity . . . Response Time (reaction time) 
in experimental research on drugs and highway safety.

\subsection{Assessing Drug Effects: Methodology}

As a group, the participants had applied a wide range of methods in research on driving performance and on the effects of drugs, including alcohol. The discussion of methodology to assess the effects of drugs reflected their experience as well as their convictions about its application to experimental research on drugs and highway safety.

Participants described four sets of methods to measure variables important to driving performance:

- laboratory-based methods

- tests of specific skills related to driving

- tests of performance using driving simulators

- vehicle-based methods

- tests of driving skills on closed courses

- tests of driving skills "on the road"

They distinguished among sets on the basis of whether the tests were conducted in a setting that involves actual driving or in a setting more traditionally termed laboratory. Each methodology, however, has its own characteristics, advantages, and limitations. Comments by participants are summarized below.

\subsubsection{Tests of Specific Skills Related to Driving. Tests of specific} human skills usually measure discrete variables related to driving performance. Some researchers in the area of drugs and driving have developed batteries of tests. In this category of behavioral methodology, the following kinds of tests are often included:

- choice reaction time (RV)

- psychomotor coordination (BV)

- attention (BV)

- vigilance (visual and auditory) (BV) 
- proprioception (perception of internal stimuli) (BV)

- standing steadiness (RV)

- flicker fusion (T)

- eye movements (RV)

- search and recognition (RV)

- peripheral vision (BV)

- subjective assessments of performance, the nature of treatment, and physiologic condition $(\mathrm{T})$

Tests such as those above refer to behavioral variables (BV, measured indirectly in terms of response variables), response variables (RV), or the technique itself ( $\mathrm{T}$ ). Many different methods exist for most tests. Many tests other than those listed above have been used to study the effects of drugs.

This type of methodology is generally characterized by the specificity of tests for the variables measured and by their sensitivity to changes in the response variables. To some extent, the sensitivity of a given test is related to its specificity for the effect or condition under study.

The advantages of specific tests for variables believed important to driving performance stem from their specificity and sensitivity. They offer a wide range of separate measures for assessing the broad spectrum of different drug effects. Which tests are selected may depend in part on the characteristics of the drug or condition under study. Because many of these tests are short in duration a large group of subjects can be handled efficiently with time for repeat testing.

This approach also has disadvantages. Participants tended to disagree on the extent to which the following disadvantages limit the value of this approach. One disadvantage is that many of the tests lack realism, often appearing unrelated to the driving task. One participant considered this point irrelevant and maintained that many performance tests--however unrelated to driving they appear--can at the same time tap common behavioral factors important to driving. The meaning of experimental 
findings for actual driving, however, requires judgments based on limited information; inferring driving impairment from decrements in discrete driving skills is still problematical. Another disadvantage mentioned is that the element of risk, which is present in actual traffic situations, is usually missing, though some researchers may consider this element unimportant. Because so many methods exist, different groups of researchers apply different methods, raising the issue of comparability. Finally, since the methods tend to be specific, measuring discrete skills, many tests would be needed to cover all the variables considered important for the study of drug effects.

\subsubsection{Tests of Human Skills Using Driving Simulators. Driving} simulation includes laboratory techniques that model the driving task. Because present technology limits attempts to reproduce actual driving performance in the laboratory, all driving simulators only approximate the driving task. Driving simulators vary in complexity and differ in their degree of technical sophistication.

In general, driving simulators incorporate specific tasks similar to the tests of human skills described above. Basic to most are measures of tracking ability, a fundamental part of driving performance. Because tracking tasks are relatively insensitive to the effects of drugs and other conditions, some simulators include secondary tasks like search and recognition. When performed simultaneously, these tasks increase the demand on the ability to process information. Behavioral variables such as visual perception, vigilance, and rate of information processing can be measured with driving simulators.

One advantage of driving simulators is that many of them appear more closely related to driving performance than simpler psychomotor tests. In other words, they may have greater "face-validity." Driving simulators can also include two or more tasks to measure several response variables during each test session.

Driving simulators have disadvantages, too. There are relatively few of these instruments--probably due to the high cost of development. Driving 
simulators differ in many respects, making comparisons among them difficult. Although they may test common behavioral variables, the response measures obtained are usually not the same. In addition, lack of funding has prevented the development of highly sophisticated instruments equivalent to those used, for example, in the training of airline pilots. Like other laboratory approaches, studies with driving simulators lack the element of risk that characterizes actual driving.

3.3.3 Tests of Driving Skills on Closed Courses. Moving the laboratory outdoors allows tests of driving skills that are vehicle-based. As one class of methodology, the closed driving course provides settings for various tests of driving skills. One participant described a basic set of driving maneuvers performed on a closed course:

- fender judgment, including parallel parking;

- chassis set, including tests on a handling oval and a slalom course;

- lane maintenance, a measure of tracking ability;

- curve negotiation;

- obstacle avoidance; and,

- controlled braking.

In addition to these, situations can be introduced to provide an element of surprise in order to test responses to emergencies and to simulate risk. With these tests a pattern of dependent measures is produced that could be used to describe the effects of drugs.

The advantages of this methodology lie in its obvious relation to driving performance. The tests employed are highly realistic compared to - laboratory tests. Although relatively few studies using this approach have examined drug effects, some participants thought the closed driving course could offer the means to assess their potential adverse effects on driving performance. Many of the variables listed in Table 3-1 could be measured. Instrumented cars might increase the power of this methodology for 
research on drugs and highway safety.

Despite its reliance on actual driving tasks, this methodology also has disadvantages. "Crude" measures of response variables are the rule, for example, the number of cones hit in a test run. The driving maneuvers integrate many behavioral variables; if impairment is observed, the question of how a driver was affected remains unanswered. In this experimental setting, the absence of other traffic largely removes the aspect of risk. Researchers cannot expose subjects to real hazards and must advise them that no possibility of injury exists. With respect to testing the effects of drugs, the time required for a full set of driving maneuvers may be relatively long, overlapping several phases of drug action. Finally; not all the critical variables may be covered by driving tests on closed courses.

\subsubsection{Tests of Driving Skills "On the Road." The second type of} methodology based on actual driving involves the measurement of performance while on the open road, in the presence of other traffic. Response variables can be scaled by observers or measured by instrumentation. One participant described studies measuring tracking ability (lateral lane position), physiological state (electro-encephalographic recordings, levels of stress hormones), and the state or set of the driver (three scales for subjective ratings) (Mackie and Miller 1978).

This methodology provides measures of many aspects of real driving performance. Since the driving task itself is used, the element of risk is present. Presumably, all the behavioral variables important to driving performance are tapped.

The disadvantages of the methodology may outweigh its advantages, however. Foremost among them are the legal and ethical constraints on studies of drug effects in this setting. Unless vehicles are highly instrumented, only gross observations are possible. Other disadvantages include the cost of developing and using instrumented vehicles and the very limited availability of those that are available. The experimental situation itself is artificial (though less so than in closed track and laboratory studies), which leaves open to question its influence on the behavior of 
subjects. This limitation, of course, is inherent in all experimental research involving human subjects.

\subsection{Approaches to the Experimental Study of Drug Effects on Driving} Performance

Among the factors to consider in developing approaches to experimentation in drugs and highway safety are the following:

- classes of available methodology;

- behavioral tests;

- subject characteristics (e.g., age, sex);

- test setting and conditions (e.g., acute vs. chronic administration of drugs, subject fatigue); and

- the range of drugs of interest.

This array of factors, each of which could be studied in relation to others, form a "multidimensional matrix" for experimental research, raising the prospect of tremendous cost for the study of drug effects on driving performance. For example, given a basic set of tests and different types of subjects, the task of determining dose-response relationships for a drug could last years. Participants were asked, therefore, to discuss possible alternative approaches, keeping in mind the aims of experimental research on drugs and highway safety.

One approach mentioned would truncate the extensive program of research required to study all the factors listed above. Ways to limit the scope of experimentation include reducing the number of behavioral variables and the types of subjects. Based on present knowledge of the driving task, important variables might be selected to assess the potential of drugs to impair driving performance. The variables listed in Table 3-1 comprise an initial set from which to identify those most critical with respect to highway safety. For initial testing, recognizing that subject characteristics do influence the effects of drugs, participants suggested that subjects be drawn from samples of convenience. In the past, most 
studies have used "normal, healthy, college-age volunteers." This would probably continue.

One participant wondered whether the approach of identifying a set of variables "over-dissected" the driving task. Others disagreed, pointing out that through evaluation the most important variables can be selected for assessing the effects of drugs. For example, among variables related to reaction time, the effects of drugs at the neuromuscular junction were considered least important. Delays in synaptic transmission--the time it takes a nerve impulse to produce a response in muscie--are small fractions of a second, and can be washed out by the influence of such variables as the ability of subjects to compensate or to detect signals. With sophisticated designs, experiments can separate out the influence of the variables subsumed under the term response time. One rationale for identifying important variables, therefore, is to probe as closely as possible the "rate-limiting steps" in human function tapped in driving performance.

Even with a limited set of behavioral variables, more than one method or test would be needed. A battery of tests would be required to assess the broad range of drugs of interest and their effects. In addition to basic tests that measure variables now considered important, other tests may be added, depending on the drug under study. For example, new drugs with novel effects may come into use, affecting skills not previously thought important to safety.

Participants noted that obtaining significant changes in several variables believed relevant to driving is persuasive evidence of a drug's potential to increase highway safety risk. This "screening approach" reduces the magnitude of effort and the number of separate studies required. It provides a sound base of information for decisions about further, in-depth testing of drugs.

Another question raised for discussion was how to determine the concentrations of drugs in body fluids associated with impairment of driving skills. How to interpret drug concentrations in body fluids from drivers is a question policymakers are asked with increasing frequency. At issue is not only the meaning of higher than therapeutic (or toxic) 
concentrations of drugs, but also the meaning of therapeutic concentrations of drugs, alone and in combination with alcohol and other drugs. Along with field surveys that collect data on the amount of drugs present in body fluids from drivers, experimental studies to define threshold concentrations for likely impairment are needed.

The need for concentration-effect studies stems from the limitations of dose-response studies. Dose-response relationships indicate the relative potency of drugs. For example, dosages in the therapeutic range for a drug may produce little change in performance measures; on the other hand, for a different drug, increased decrements in driving skills may be observed even within therapeutic ranges. Unfortunately, the dose of a drug is only an indirect indicator of drug concentration in body fluids. That increasing the dose of a drug increases impairment of driving skills can be expected; even water, taken in excess, can influence behavior. In traffic-related cases, information about the dose of drug taken will be limited, if available at all. Data will be limited to results of chemical tests, reported in terms of drug concentrations. Thus, data on concentration-effect relationships are also needed to aid in the interpretation of analytical results in traffic-related cases. This kind of data can be obtained in conjunction with dose-response studies, provided blood specimens are obtained at appropriately timed intervals throughout the course of behavioral testing.

Figure 3-1 illustrates one way to view the relationship between concentrations of drugs in body fluids and the likelihood of impaired driving. In general, the greater the concentration of a drug at a point in time, the more intense its effects. Side effects (effects other than those for which the drug is used) may also appear and intensify. Three general zones representing the relative intensity of a drug's effects may be described in relation to the driving task. Low, subtherapeutic concentrations (or doses) would probably not impair driving skills; this is the "impairment unlikely" zone. Between this zone and the zone of likely impairment (associated with higher concentrations or doses of a drug), an intermediate, ill-defined zone occurs. This zone indicates where drug 
FIGURE 3-1

CONCENTRATIONS OF DRUGS IN BODY FLUIDS AND THEIR EFFECTS: THE LIKELIHOOD OF DRIVING IMPAIRMENT.

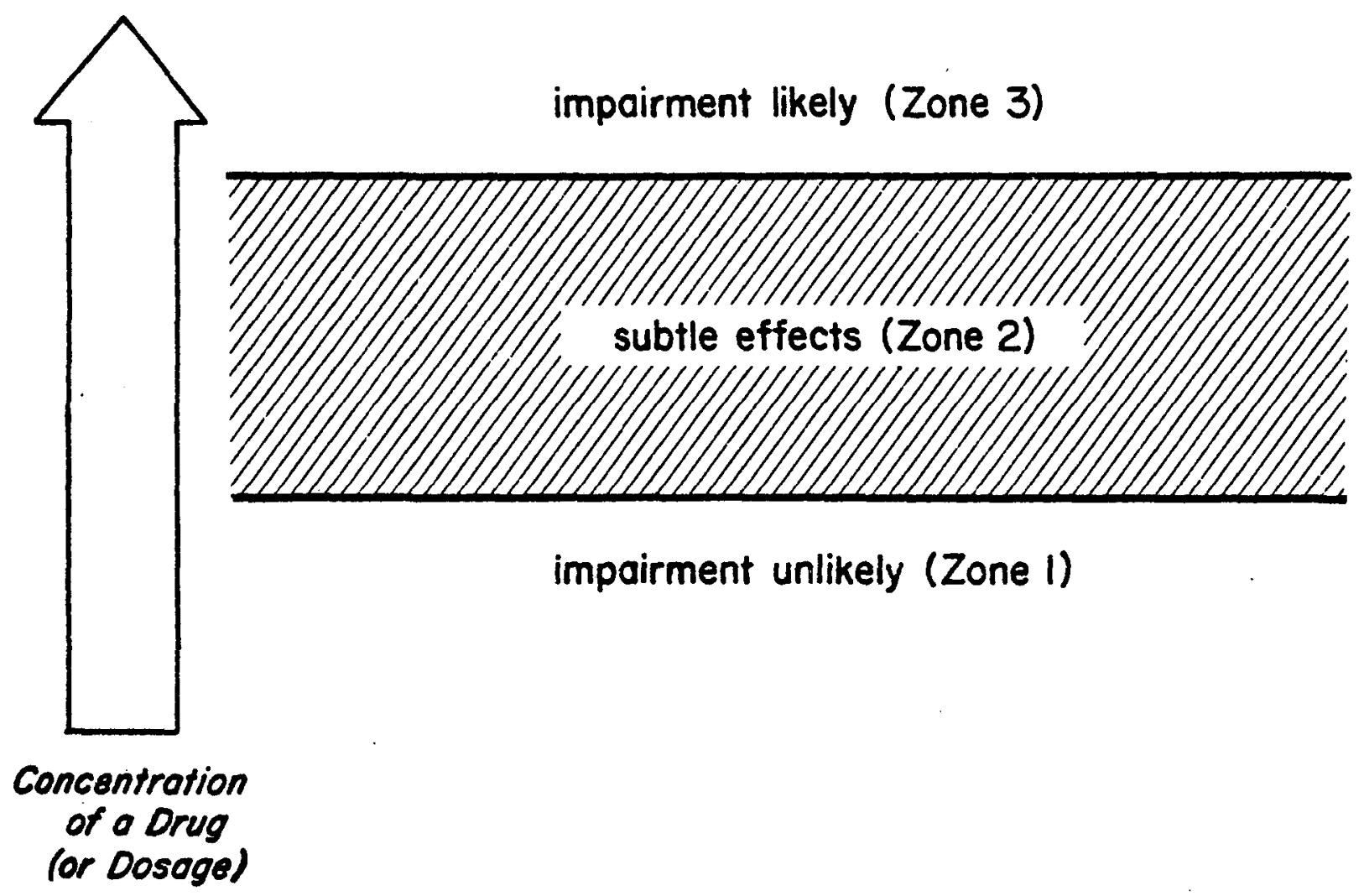


effects that are subtle may still impair driving and increase highway safety risk. Although these zones are demarcated by lines, variability among drivers and subjects in experiments would result in a range of overlapping values for each threshold.

.How great the overlap between zones and how great the uncertainty over borderline values depend on many variables, including drug and personal characteristics. In addition, the variable of time has not been considered in Figure 3-1. Drug effects are time-dependent. Moreover, the relationship between concentration and effect is not necessarily linear over time. For example, the behavioral effects of some drugs are more pronounced sooner after administration, when concentrations in body fluids are rising, than later at identical concentrations, when they are falling.

Other factors and conditions complicate the simplistic view presented in Figure 3-1. For example, disease conditions may impair driving skills. Therapeutic drugs, properly prescribed and taken according to instructions, may reduce the adverse effects of disease on driving ability. This is illustrated in Figure 3-2. If dosages of therapeutic agents are increased, however, side effects and toxic reactions that can impair driving can be observed. Unfortunately, studies of drug effects on driving skills in patient populations are few; drug-disease-driving interactions have not been characterized for the most part. It may be that appropriate drug treatments of diseases that impair driving skills do not return driving ability to "normal," or that only some portion of the patient population experiences improvement. These are issues that experimental drug and driving research can help resolve.

The literature on drug effects reflects an emphasis on testing for the "subtle" effects of drugs (see Figure 3-1). The issue of requirements for specificity in behavioral research was raised. Tests of discrete skills appear more sensitive than required for the higher concentrations of drugs of interest in highway safety. Besides more complex testing around the lower threshold, perhaps simpler protocols to indicate the higher threshold should be emphasized. The determination of the threshold for likely impairment may not require the sophistication in methodology now applied 
FIGURE 3-2

THERAPEUTIC DRUGS AND THEIR POSSIBLE EFFECTS ON DRIVING SKILLS IN PATIENT POPULATIONS

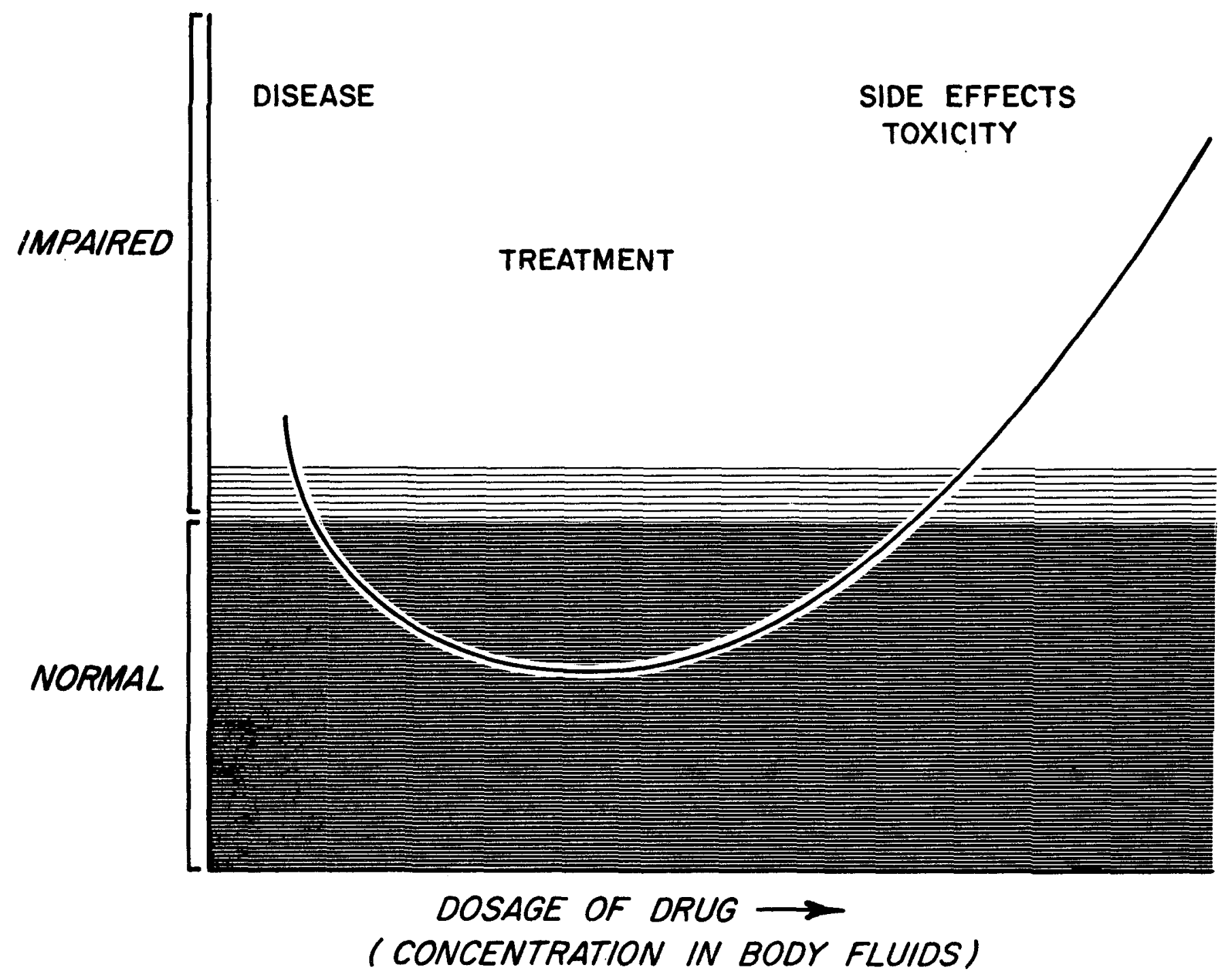


to describe the subtle effects of drugs. However, no tests that could be used as a matter of routine for this purpose have been identified, however.

Participants defended efforts to characterize the second zone of drug effects. For example, the process involved in the development and marketing of therapeutic drugs reduces the likelihood of obvious impairment. The pharmaceutical industry approaches the higher threshold very carefully; the recommended therapeutic dosages reflect the concern of manufacturers for the viability of their product in a highly competitive market. In clinical trials, specific tests for each drug are used to determine the most likely beneficial dose with the fewest side effects. Drugs that produce obvious impairment are withdrawn. Moreover, for drugs now in use, there are significant constraints on experimental studies of higher than normal therapeutic dosages of drugs in human subjects.

One participant compared research on alcohol to that on other drugs. At a blood alcohol concentration (BAC) $0.10 \% \mathrm{w} / \mathrm{v}$, some people--for example, frequent or heavy users of alcohol--will not show obvious impairment of actual driving performance. The average BAC of drivers arrested for driving while intoxicated is in excess of $0.15 \% \mathrm{w} / \mathrm{v}$. Yet an increased probability of accident-involvement occurs at much lower levels. Laboratory tests indicate impaired performance at lower BACs, consistent with accident risk. "Less than obvious" impairment may still increase highway safety risk. Some participants thus expressed their conviction that these complex tests are required for this range of more subtle effects produced by alcohol and other drugs.

Participants also stated that no general test now exists that will indicate impairment of driving performance for a given concentration of a drug. The dimensions of impairment are just not known. The state of the art in behavioral research methodology as well as the state of knowledge of the relationship between drug concentrations and their effects are presently too limited. Experts in forensic toxicology who testify about the meaning of drug concentrations might apply "rules of thumb," defining impairment as five to ten times average therapeutic levels. But there are as yet no definite measures of driving impairment based on drug 
concentrations in any body fluid. It is doubtful adequate data exist at present to establish presumptive limits for any drug other than alcohol. One participant said that he would be "very hesitant" to ascribe meaning to the amount of a drug in body fluids without data on the time of ingestion and the length of time the person had used the drug. Such information is rarely available in field surveys of drug use among drivers unless substantial efforts to collect collateral data are undertaken.

Addressing the question of how to determine the threshold of likely impairment, participants stressed that no quick, simple approach was possible. A wide range of tests is available; applied to this problem, they would provide a set of concentration-effect relationships for each drug. The accuracy of their results and the cost of obtaining them depend on the number of different doses studied, the number of subjects included in each study, and the degree of intersubject and intrasubject variablity found. In the laboratory, low, medium, and high doses of drugs should be used, along with a placebo, to construct dose-response curves. Baseline performance should be established prior to drug or placebo. administration. Subject variability alone prevents the use of a single dose compared to a no-treatment condition. The use of placebo and three dosage levels approximates the dose-response relationship and, combined with chemical tests of body fluids, a threshold for likely impairment can at least be estimated.

Unfortunately, even the relationship between dose and response for any drug is not simple. The correlation of a drug's concentration in body fluids and its effects on behavior adds another degree of complexity. Many factors will influence attempts to define the threshold for likely impairment. Figures 3-3a-e show hypothetical, idealized dose-response curves altered by experimental factors mentioned by participants. One behavioral test may be more sensitive than another, its performance criterion showing impairment at lower dosage levels (3-3a). In complex tests of behavior, one of several simlutaneous measures may show impairment at lower doses than another (3-3b). Different populations of subjects may differ in their response to a drug; for example, subjects more 
FIGURE 3-3. DETERMINING THE THRESHOLD FOR LIKELY IMPAIRMENT: FACTORS THAT INFLUENCE DOSE-RESPONSE (CONCENTRATION-EFFECT) RELATIONSHIPS.
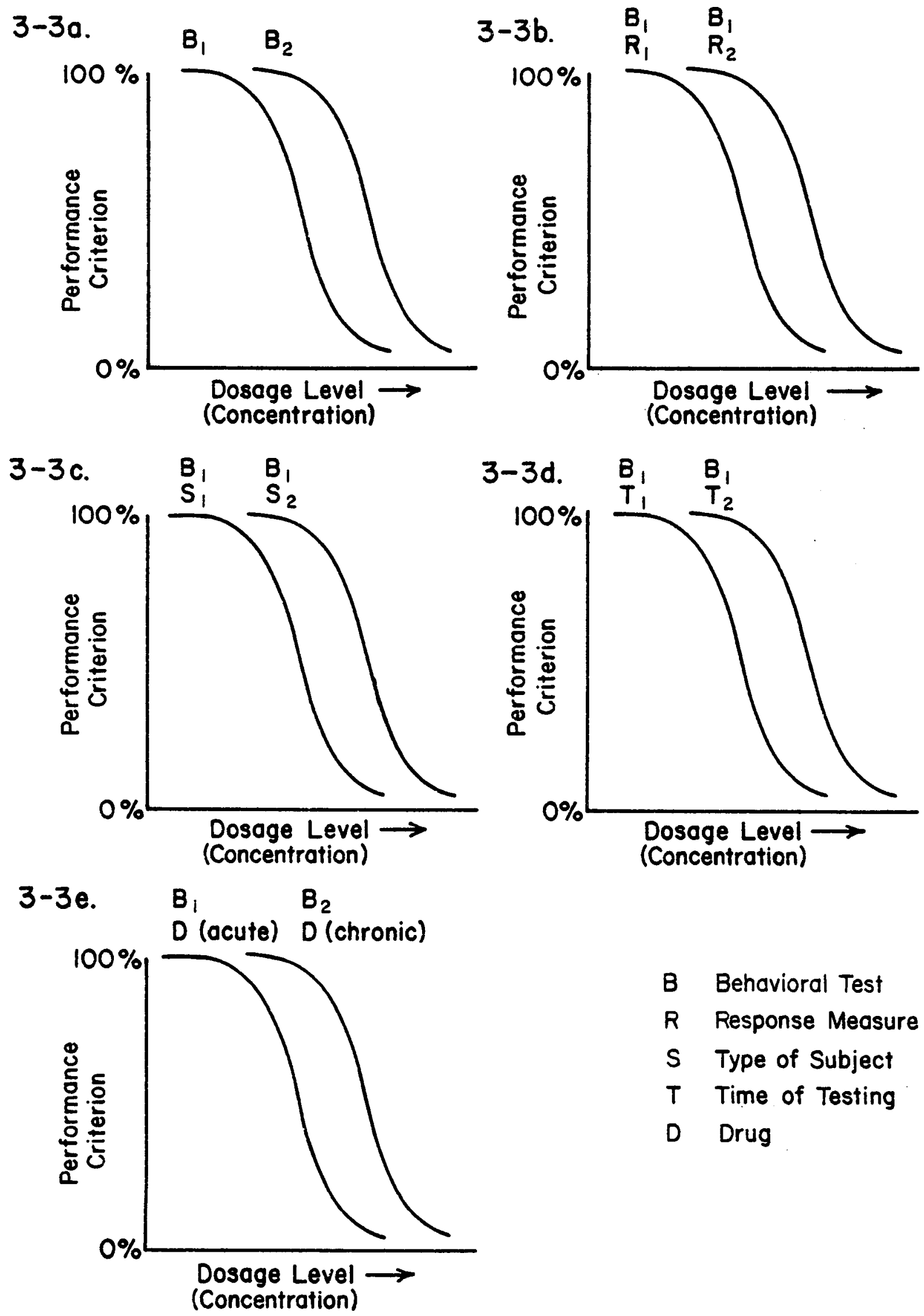
B Behavioral Test
$R$ Response Meosure
$S$ Type of Subject
$T$ Time of Testing
D Drug


susceptible to the effects of a drug may be impaired at lower doses when compared to other groups of subjects (3-3c). When the effects of a drug are measured may also alter dose-response relationships. Testing before or after the time of peak drug effect $(\mathrm{T})$ would shift the curve to the right, indicating impairment at higher dosage levels (3-3d). The acute and chronic administration of drugs may also lead to two sets of dose-response curves, for example, if tolerance to a drug's effects were produced in subjects receiving doses at regular intervals (3-3e). Of course, greater effects may also be observed with chronic dose regimens, depending on the type of drug and the dosage schedule. This would reverse the relationship between the curves shown in Figure 3-3e.

The central issue in these discussions was the sensitivity of tests needed to indicate the threshold for likely impairment. A test's sensitivity is a function of its specificity for the kind of effects produced by a drug. Sophistication in technology also plays a role, increasing the precision of measuring small changes in response variables. Given a set of tests with a range in sensitivity, a set of dose-response curves would result from the experimental study of drug effects. One criterion-the relevance of each test to safe driving performance--was seen as essential for comparing methods to determine the concentrations of drugs in body fluids associated with driver impairment.

\subsection{Comparing Behavioral Methodologies: The State of Knowledge}

Although participants generally agreed on the types of variables that should be measured, they failed to reach consensus on the "best" methods for measuring them. The basic disagreement appeared to stem from biases developed from their research experience. In discussions comparing the classes of methodology discussed in Section 3.3, the group revealed a dichotomy in their analysis of the driving task.

The two sets of behavioral methodology described by participants were characterized as micro ("laboratory" tests) and macro (vehicle-based tests). They emphasized two different aspects of test specificity. The micro approach tends to be more specific with respect to behavioral variables 
affected by drugs. The macro approach is more specific to some aspects of driving performance, particularly in the integration of skills needed in driving. Each methodology is based on analyses of human factors associated with accident causation and skills needed to prevent accidents.

One participant thought that the apparent duality between micro and macro approaches arises from two separate questions:

- What are the effects of drugs on performance of human skills?

- What are the effects of drugs on driving performance?

The first question stresses the mechanism of drug effects, the second emphasizes relevance to the driving task. Researchers favoring the micro approach attempt to define behavioral variables important to driving performance and employ specific tests to measure them. Researchers who advocate the macro approach attempt to approximate the driving task itself by using tests of actual driving. The distinction between approaches rests with psychologically defined mechanisms and the actual operation of motor vehicles, with specific versus global measures.

This same participant also stated that, given the present state of knowledge, no inherent contradiction between approaches exists. Before judgment between them is possible, some assessment of which variables are critical in the precipitation of accidents is necessary. For the most part, the variables listed in Table $3-1$ can be measured both in the laboratory and on closed driving courses. The approaches are not mutually exclusive. For example, training programs based on driving maneuvers have been associated with a reduction in accidents. Crude as they may appear, driving maneuvers tap something relevant to highway safety. Although the closed driving course does not provide unitary measures for behavioral variables, the hallmark of laboratory tests, it may be more specific to some real problems of driving. Nevertheless, in determining not only how but also if drugs have a significant risk potential, some laboratory tests may be required to measure behavioral variables otherwise not tested on closed driving courses. 
Furthermore, macrobehavioral and microbehavioral research on drug effects complement each other in studies of two related phenomena: the ability to compensate for decrements in skills when driving and the ability to cope with the effects of a chronically administered drug (state dependent learning). Laboratory-based studies may identify one or more skills related to driving that are impaired by a drug at certain dosages. The question of how well a person can compensate for this skill reduction requires a method that reproduces the driving task as fully as possible, for example, closed course driving tests. The long-term (chronic) use of a drug may lead to behavioral adaptation; a person may learn to respond to behavioral demands in driving with no apparent reduction in skills. Both laboratory- and vehicle-based methods can be used to advantage for studying drug effects in relation to the driving task.

The point was made that there is as much need to validate methodology based on actual driving against the real criterion--safety--as there is for tests run in the laboratory. Because the relative importance of behavioral factors and variables is not known for the driving task, because their relative importance may vary with different driving settings and driver conditions, and because drugs may alter their relative importance, both micro and macro approaches are required at this time for an adequate assessment of drug effects on driving skills. No single experimental paradigm can supply all the information needed to describe the potential highway safety risk of drugs.

\subsection{Summary}

In summary, participants discussed and compared different approaches to experimental research on drugs and highway safety. The aims of experimental research in this area--to assess the potential highway safety risk of drugs and to specify concentrations of drugs in body fluids associated with driver impairment--guided this discussion. Participants identified factors important to the study of drug effects on driving performance and described four classes of behavioral methodology for use in this research. The present state of knowledge prevents final judgment 
concerning those variables most critical in accidents involving drugs and the best methods to evaluate drug effects. Numerous factors complicate attempts to determine threshold concentrations of drugs that indicate likely driver impairment. No one study or technique will yield all the information needed. Each type of methodology has certain advantages. A comprehensive program of experimental research on drugs and highway safety will require some combination of these techniques. 


\subsection{OTHER ISSUES IN EXPERIMENTAL RESEARCH ON DRUGS AND HIGHWAY SAFETY}

In addition to questions directly concerning methodology, participants discussed other issues related to experimental drug and driving research

- comparability among experimental studies;

- alcohol as a standard reference drug for experimental research on other drugs;

- the selection of experimental subjects; and

- the face validity of experimental research findings for drugs and highway safety.

These topics are summarized in the subsections below.

\subsection{Comparability Among Experimental Studies}

Past research reviews have noted the number and diversity of experimental studies related directly or indirectly to drugs and driving. In this workshop, three types of studies were defined:

- studies with methods designed specifically to evaluate a given drug and its effects;

- studies with methods designed to test some aspect of human performance, with which the effects of drugs were studied; and,

- studies with methods designed to reproduce some part of the driving task, with which the effects of drugs were measured.

In general, these types of studies have little in common. The difficulty in comparing studies of a given drug is further enhanced by differences in experimental design and the populations of subjects. Overall, there have been very few systematic attempts to study a variety of drugs with the 
same methodology, and even fewer attempts to correlate findings between methods. The requirement to do many kinds of studies to obtain adequate information in the area of drugs and driving makes the issue of comparability in research especially critical.

Several ways to enhance comparability in experimental research were suggested. A standardized battery of tests could be used in different laboratories to increase the power of behavioral research on drug effects. Research to establish correlations among different methods on some behavioral variables could be done. The results of tests in different laboratories could be compared using instrumented cars.

Participants also noted constraints on obtaining greater comparability. These included the views of individual scientists preferring certain methods over others and, therefore, the probable lack of universal acceptance of a standardized test system. The state of knowledge itself does not allow the design of an international system for testing the effects of drugs on driving performance. Each investigator has developed or applied behavioral methods based on an analysis of how best to describe changes in performance in relation to the driving task.

\subsection{Alcohol as a Standard Reference Drug for Experimental Research on} Other Drugs

Another approach to increase comparability in experimental research involves the inclusion of alcohol as a reference drug in the design in behavioral tests. The rationale for this suggestion was that, given the improbability of a common battery of tests, the effects of. alcohol might provide some standard for comparing different studies of other drugs.

Participants pointed out several problems with this approach. First, the profile of effects varies from drug to drug; many drugs differ greatly from alcohol in their effects on behavioral variables. Second, drugs differ in their onset and duration of action. Variations in their bioavailability and pharmocokinetics would complicate any attempt to compare the effects of alcohol and other drugs in the same experimental design. Third, the question of what concentrations of alcohol should be the basis of 
comparison is difficult to answer. Tests of performance showing impairment by alcohol at a BAC of $0.10 \% \mathrm{w} / \mathrm{v}$ may be too insenitive for other drugs. On the other hand, some tests of important behavioral variables not impaired by alcohol at $0.10 \% \mathrm{w} / \mathrm{v}$ may show significant effects by other drugs. These problems, in the view of the participants, prevent the use of alcohol as a general standard for assessing the potential highway safety risk of other drugs.

\subsection{The Selection of Experimental Subjects}

An issue related to comparability in experimental research, the selection of subjects for studies of drug effects, was discussed. Two related questions in this area are:

1. How do we select a subject population?

2. Which subject populations are appropriate for research on the potential highway safety risk of drugs?

A basic dilemma in experimental research involves the dual concerns of intersubject variability and the meaning of significant drug effects for the general driving population. The selection of closely matched, homogeneous groups of subjects can reduce the problem of statistical variance in response measures. On the other hand, since these groups of subjects are usually not representative of the general population--or even of the population that uses the drug-this approach prevents simple extrapolation of significant drug effects to the population at risk.

Participants differed to some extent in their estimation of the importance of subject selection. One participant cited his research on judgment in driving. Methodology developed in a pilot study using college sophomores, when extended to a sample of drivers selected at random in driver licensing stations, produced extremely poor correlations. He saw the need for completely stratified samples. Another participant disagreed, referring to studies that give comparable results in patients and healthy volunteers with antianxiety and antidepressant agents.

Assessing the potential highway safety risk of therapeutic drugs requires 
several comparison groups of subjects. As illustrated in Figure 3-2, certain diseases--for example, diabetes, anxious states, epilepsy, and some cardiovascular conditions--can impair driving. Treatment of medical conditions may actually improve a patient's driving ability. The simple comparison of drug and nondrug conditions in an experimental study employing normal, healthy volunteers may be misleading. In this subject population, the effects of the therapeutic agent do not contribute to regaining body functions, and no enhancement of ability is expected. Moreover, in many studies, behavioral tests are designed only to measure decrements in skills. To assess the effects of therapeutic drugs--both positive and negative--several comparison groups are required, including patient groups and healthy volunteers, both with and without treatment and before and after treatment.

Participants noted that many subject-related factors can influence the relationship between concentrations of drugs in body fluids and their effects. Among these factors are the following:

- age;

- sex;

- tolerance and cross-tolerance to the effects of a drug;

- ability to compensate for the effects of a drug;

- differences in the absorption, protein binding, and metabolism of a drug; and,

- circadian (24-hour) and ovulatory rhythms.

Other differences among subject populations may be more subtle. For example, recent research in neurophysiology indicates that the hemispheres of the brain differ in function. Spatial information is processed in the nondominant hemisphere, whereas verbal information is processed in the dominant hemisphere. In subject populations like college students with highly trained centers of verbal skills, the ability to process spatial information may be much more impaired. Other subject populations may respond to the effects of same drugs differently. 
Several approaches to the selection of subjects for the study of drug effects were mentioned. One approach is based on epidemiologic research. Assuming that drug use in driving populations is associated with certain driver characteristics, subjects with corresponding characteristics might be selected for experimental research. Lacking such information, the selection of subjects could be based on the predominant types of users of a drug. For example, some drugs of interest are mainly used by women of middle age. Another approach would use a restricted population of subjects for the initial screening of drug effects. The perennial sample of convenience--normal, healthy, male students of college age-was suggested. Researchers should at the same time recognize that other factors may interact with the effects of certain drugs, and these should be studied later for a complete assessment.

Some participants stated that while biological and social factors related to age did influence the response to drugs, they did not expect a reversal of findings of significant effects. Others voiced concern that significant effects in other populations might be missed by the approach based on a single type of subject. Alternatives to college-age subjects were suggested, including commercial drivers of middle age and police officers. Another type of subject of potential interest is the elderly driving population. The elderly, who comprise about ten percent of the driving population, account for twenty-five percent of the prescriptions filled in the United States.

\subsection{The Face Validity of Experimental Research on Drugs and Highway} Safety

A secondary issue in research on drug effects relates to the acceptance of the results of experimental studies by policymakers in the area of highway safety. This issue was raised several times in discussions of the type of methods to assess the influence of drugs on driving performance. The main point is that, in driving research, "everybody is an expert." This places greater weight on the factor of credibility of scientific research in this area. Results obtained with tests that bear little resemblance to 
driving face an uphill struggle in influencing the perception of risk by drivers. Aside from sophisticated laboratory tests of higher cognitive functions, even driving simulators may not have the face validity necessary to convince people of the practical meaning of significant drug effects.

In discussing this issue, participants cited evidence supporting the validity of laboratory-based methodology. For example, dose-response curves obtained for alcohol approximate its relative risk curve. Effects of alcohol on specific tests are observed at similar BACs where the relative probability of a traffic crash increases. The likelihood that similar data can be obtained for other drugs in the near future is small, however.

Approaches to increase the face validity of experimental studies in cluded:

- showing drug effects on a battery of tests assessing variables that are relevant--and relatively important--to safe driving;

- demonstrating that laboratory tests of behavioral variables correlate well with the same kind of functions measured by tests of actual driving;

- validating experimental findings of significant drug effects by conducting field surveys of drugs in populations of accident- and nonaccident-involved drivers; and

- linking the impairing effects of alcohol with other drugs in experimental studies.

The last approach, of course, assumes all the problems noted above in section 4.2 .

\subsection{Summary}

In summary, participants discussed issues related to methodology in experimental research on drugs and highway safety. Noting the lack of commonality among studies of drug effects, they suggested ways to increase comparability of studies. At the same time, they observed that certain constraints may frustrate these attempts. Participants argued against the use of alcohol as a standard in studying the potential of drugs 
to impair driving skills. Although the selection of experimental subjects for preliminary testing of drug effects might be limited to a special population, participants also mentioned subject-related factors that should be considered in a comprehensive assessment of the potential highway safety risk of drugs. Finally, approaches to enhance the face validity of experimental research were outlined. 


\subsection{CONCLUSIONS AND RECOMMENDATIONS}

Research has yet to define the problem of drugs and driving. Information to describe the relationship between drugs and highway safety is obtained by two general approaches, epidemiology and experimentation. Experimental studies of drug effects on driving-related skills account for most of the literature on drugs and driving. Despite the volume of research, knowledge remains fragmentary. Separate studies are rarely comparable, and no unified body of knowledge has developed. In addition, methodological problems abound, hindering progress in this area of research. As an aid to planning further research on drugs and highway safety, this workshop focused on methodological issues.

The aims of experimental drug and driving research include the following:

- to assess the potential highway safety risk of drugs;

- to characterize the effects of drugs on driving performance; and

- to establish the meaning of drug concentrations in body fluids for impairment of driving performance.

The following major topics related to these aims were discussed by participants:

- variables important for the study of drug effects in relation to the driving task;

- behavioral methodology to measure the effects of drugs on driving skills; and

- experimental approaches to research on drugs and highway safety.

The panel identified behavioral and other factors associated with driving performance, ranging from psychomotor skills to complex, higher cognitive 
functions. Participants stressed that the present state of knowledge limits any attempt to define critical variables in relation to the driving task. Even for those variables discussed in this workshop, much research remains to determine their relative importance. Because the drugs of interest have a wide range of effects, more than one or two variables need testing. The obvious conclusion was drawn--that no one study can answer all the questions about the potential highway safety risk of drugs.

Participants described several classes of methodology for measuring variables related to driving performance. They acknowledged that the state of the art in behavioral research methodology itself is limited for the purposes of 'experimental research on drugs and highway safety. Methods are still evolving, as are the test paradigms needed to infer the kinds of impairment resulting from the effects of psychoactive drugs.

Nevertheless, the panel pointed out that, given all their limitations, sets of relevant tests now exist for application in drug and driving research. Which tests are selected may depend on the mission of funding agencies. Each methodological approach, however, was as likely as another to produce information of use in the near term. This group of researchers did not recommend a choice among them for NHTSA. The classes of methodology are not mutually exclusive, but interactive. Differences between laboratory-based and vehicle-based tests suggest that both are needed to fully assess drug effects on driving skills.

Many factors must be considered in the design and conduct of experimental research to describe the potential highway safety risk of drugs. In fact, test-, subject-, and drug-related variables are so numerous that some simplified--but scientifically acceptable--approach is required in this area. Participants noted that possible approaches range from the "quick and dirty" (e.g., a single behavioral test involving normal healthy college students) to the more rigorous, highly costly designs that control for important, interactive factors like age, sex, drug dosage regimens, etc. They suggested that a screening system be developed, limiting the number of variables and types of subjects to be tested. More intensive research efforts might be reserved for drugs shown to have significant effects in 
initial testing or that appear overrepresented in crash populations.

At the same time, participants stood firm against the possibility of quick answers. For definitive answers, especially with respect to the meaning of drug concentrations in body fluids for driver impairment, concentration-effect curves must be developed. Attention to crucial elements of experimental design is needed to ensure the highest accuracy, whichever tests are applied to the problem.

Presently, no single paradigm for the study of drug effects exists, and many kinds of studies are required to build an adequate base of information. This conclusion underscored the issue of comparability in experimental research. Recognizing its importance, the panel held out little hope for standardization in the study of drug effects on driving skills. In particular, participants argued against using alcohol as a reference drug in behavioral research on other drugs.

Asked to list priorities for research in the near term, participants developed a set of recommendations for future directions of experimentation in drugs and driving. As in other workshops in this series, they cited the need to compile all relevant information for the design and conduct of research. Other sources besides epidemiologic and experimental research should be tapped, including pharmacologic data, both human and animal; industrial studies of drug use and drug effects on the performance of workers; and statistics from the Drug Abuse Warning. Network (DAWN). In particular, data should be gathered by local agencies in different jurisdictions on the amounts of drugs found in body fluids from drivers. This information would provide some idea of the concentrations of drugs associated with driver impairment for experimental studies.

There is also a continuing need to better understand the driving task in terms of the types of behavior associated with accident causation. Participants recommended further efforts to define a set of critical variables for the study of drug effects on driving performance. In addition, factors that influence experimental findings and their implications for safety should be identified. Even though all these factors cannot be dealt with simultaneously in a single study, an awareness of them is 
essential for future research to assess the potential highway safety risk of drugs.

Participants also recommended that NHTSA consider funding research on behavioral methodology related to driving performance. Research is required to compare different methodological approaches. Indeed, all classes' of behavioral methodology must be correlated and validated for their application in the area of drugs and driving. Their utility for measuring variables in relation to the driving task should be established. Simpler tesțs of drug effects on driving performance may evolve from the analysis of existing tests.

The panel recommended that NHTSA should sponsor longer term, more comprehensive efforts in this and other areas of research. Realizing this concern appeared self-serving, these researchers based the suggestion on the need for greater continuity for work in complex fields. The advantages of longer term funding included (l) the improved capability for defining and resolving problems at the core of research issues and (2) more sustained progress in advancing the state of knowledge. Along with its emphasis on drivers of passenger cars, the U.S. Department of Transportation might expand research on drugs and their influence on human performance to other areas, for example, commercial carriers and waterway operations.

Finally, participants recommended that NHTSA promote a greater exchange of information among policymakers and researchers. Although groups of researchers are funded by several agencies with different missions, their efforts are basically related. Better communication among researchers might result in better coordination of research on drugs and their effects, and in increased comparability of separate studies.

In their final comments, participants stressed that behavioral tools are available for experimental research on drugs and highway safety. No one of these tools is a panacea, but as a set of methodological approaches, they can be applied to increase the precision of present knowledge. At the same time, research on methodology will provide insight into further development of the methods themselves. 
APPENDIX A

LIST OF WORKSHOP IV PARTICIPANTS 


\section{APPENDIX A \\ DRUG RESEARCH METHODOLOGY \\ EXPERIMENTATION IN DRUGS AND HIGHWAY \\ SAFETY: THE STUDY OF DRUG EFFECTS \\ ON SKILLS RELATED TO DRIVING}

\section{LIST OF WORKSHOP PARTICIPANTS}

This workshop was held on 19-21 June 1978. The following persons participated; their titles, positions, addresses, and telephone numbers are those at the time of the workshop.

Stephen D. Benson, Ph.D. NRD-42

Contract Technical Manager

U.S. Department of Transportation

National Highway Traffic Safety Administration

Trans Point Building

2100 Second Street, S.W.

Washington, D.C. 20590

(202) $426-2977$

David K. Damkot, Ph.D.

Department of Psychology

University of Vermont

John Dewey Hall

Burlington, VT 05405

(802) $656-2670$

Alan C. Donelson, Ph.D.

Assistant Research Scientist

Highway Safety Research Institute

The University of Michigan

Huron Parkway at Baxter Road

Ann Arbor, MI 48109

(313) $763-1276$

Leon G. Goldstein, Ph.D.

8209 Ellingson Drive.

Chevy Chase, MD 20015

(301) $587-4130$ 
Kent B. Joscelyn, J.D.

Head, Policy Analysis Division

Highway Safety Research Institute

The University of Michigan

Huron Parkway at Baxter Road

Ann Arbor, MI 48109

(313) $763-1276$

Rodger J. Koppa, M.A.

Head, Human Factors Division

Texas Transportation Institute

Texas A\&M University

College Station, TX 77840

(713) $779-3880$

Norman A. Krasnegor, Ph.D.

Acting Chief, Clinical Behavioral Branch

Division of Research

National Institute on Drug Abuse

Parklawn Building, Room 921

5600 Fishers Lane

Rockville, MD 20857

Markku Linnoila, M.D., Ph.D.

Head, Clinical Psychopharmocology

Box 2921

Duke University Medical Center

Durham, NC 27710

(919) 684-2044

Roger P. Maickel, Ph.D.

Professor of Pharmacology and Toxicology

Head, Department of Pharmacology and Toxicology

School of Pharmacy and Pharmacal Sciences

Purdue University

West Lafayette, IN 47907

(317) $494-8430$

Herbert Moskowitz, Ph.D.

Southern California Research Institute

6305 Arizona Pl.

Los Angeles, CA 90045

James C. Miller, Ph.D.

Research Physiologist

Human Factors Research, Inc.

5775 Dawson Avenue

Goleta, CA 93017

(805) 964-0591 
Robert E. Willette, Ph.D.

Chief, Research Technology Branch

National Institute on Drug Abuse

Parklawn Building, Room 942

5600 Fishers Lane

Rockville, MD 20857

(301) $443-5280$ 


\section{BIBLIOGRAPHY}

Joscelyn, K.B., and Donelson, A.C. 1979. Drugs and driving: A selected bibliography. Supplement one. National Highway Traffic Safety Administration technical report DOT-HS-803-879.

Joscelyn, K.B., and Donelson, A.C. 1980. Drug research methodology. Volume two. The identification of drugs of interest in highway safety. National Highway Traffic Safety Administration technical report DOT-HS805-299.

Joscelyn, K.B.; Jones, R.K.; Maickel, R.P.; and Donelson, A.C. 1979. Drugs and driving: Information needs and research requirements. National Highway Traffic Safety Adinistration technical report DOT-HS-804-774.

Joscelyn, K.B., and Maickel, R.P. 1977a. Drugs and driving: A research review. National Highway Traffic Safety Administration technical report DOT-HS-802-189.

Joscelyn, K.B., and Maickel, R.P. 1977b. Drugs and driving: A selected bibliography. National Highway Traffic Safety Administration technical report DOT-HS-802-188.

Mackie, R., and Miller, J.C. 1978. Effects of hours of service, regularity of schedules, and cargo loading on truck and bus driver fatigue. Goleta, California: Human Factors Research, Inc. Report no. 1765-F.

Organanisation for Economic Co-operation and Development. 1978. New research on the role of alcohol and drugs in road accidents. Paris, France: OECD.

Seppala, T., Linnoila, M., and Mattila, M.J. 1979. Drugs, Alcohol and Driving. Drugs 17:389-408.

Willette, R.E., ed. 1977. Drugs and driving. National Institute on Drug Abuse Research Monograph 11. U.S. Department of Health, Education, and Welfare publication no. (ADM) 77-432. 